\title{
A rolling-horizon optimization algorithm for the long term operational scheduling of cogeneration systems
}

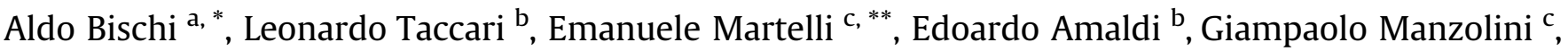 \\ Paolo Silva ${ }^{\mathrm{c}}$, Stefano Campanari ${ }^{\mathrm{c}}$, Ennio Macchi ${ }^{\mathrm{c}}$ \\ a Center for Energy Systems, Skolkovo Institute of Science and Technology, Moscow, Russian Federation \\ b Dipartimento di Elettronica, Informazione e Bioingegneria, Politecnico di Milano, Milano, Italy \\ c Dipartimento di Energia, Politecnico di Milano, Milano, Italy
}

\begin{abstract}
A rolling-horizon algorithm is proposed for optimizing the operating schedule of a given cogeneration energy system while taking into account timevariable loads, tariffs and ambient conditions, as well as yearly fiscal incentives. The presented algorithm is based on the Mixed Integer Linear Programming (MILP) model developed by the authors for optimizing the daily schedule of cogeneration systems and networks of heat and power plants.

First the MILP model is extended to optimize the weekly operation schedule to better manage the heat-cold storage systems. However, in order to account for the European qualification framework for high efficiency cogeneration, as well as for country-specific incentive policies, it is necessary to consider average yearly-basis energy saving indexes, thus requiring to tackle the problem for the whole year. Since the extension of the MILP model from one day to seven days already increases remarkably the computational requirements, a simple application of the same optimization approach to a whole year would be practically unfeasible; therefore, this work proposes a rolling-horizon algorithm in which a sequence of weekly MILP submodels is solved, while considering production and consumption estimates based on demand profiles from historical data. The results obtained for a real-world test case are re-ported and discussed.
\end{abstract}

\section{Introduction}

\subsection{Combined heat and power (CHP) and fiscal incentives}

Cogeneration, also known as Combined, Heat and Power (CHP), represents an efficient and cost-effective way to reduce at the same time primary energy consumption and carbon dioxide emissions [1]. CHP makes a rational use of primary energy (fuel) which is converted simultaneously in electric/mechanical power and heat for a set of users; refrigeration effect can also be produced as in a cascade process, either utilizing electricity or heat, being labeled Combined Cooling, Heat and Power (CCHP). For a properly designed and operated system, this yields a quite significant primary energy saving - with advantages also in terms of $\mathrm{CO}_{2}$ emissions- with

\footnotetext{
* Corresponding author.

** Corresponding author.

E-mail addresses: a.bischi@skoltech.ru (A. Bischi), emanuele.martelli@polimi.it (E. Martelli).
}

respect to the separate generation of electric power, heat and/or cooling effect. Thanks to their energy and environmental friendliness, cogeneration systems are also favored by the incentive policies adopted in several countries like European Union [2] and United States of America [3] and are acknowledged being important in other countries like Russian Federation where a large share of the installed thermal power, about one third [4], is cogenerative. In this paper we will focus on the European Union policy framework for the qualification of high efficiency CHP systems, valid for all the member states, then focusing on the Italian legislation which allows the high efficiency cogeneration to obtain incentives called "white certificates" [5,6]. Several types of prime movers are suitable for cogenerative applications, ranging from micro-turbines and internal combustion engines to gas-steam turbine combined cycles [7]. The prime movers can be classified on the basis of their number of independent operative variables, here called "degrees of freedom". Heat can be recovered from the above-mentioned prime movers at different temperature levels, depending on both customer requirement and plant design. Other systems such as 
heat pumps, refrigeration units and conventional boilers can be also included in a CHP system. In addition, heat storage systems can be adopted and, in presence of different heat recovery circuits, high temperature heat can be downgraded from high to low temperature.

As discussed in a previous article [8], the operation of CHP systems poses a number of challenges due to the fact that in many instances electric power, heat and - nowadays increasingly refrigeration power demands do not follow the same time profile and different units can be used to satisfy the user demands. As an additional challenge, the above-mentioned cogeneration incentives are typically granted on a yearly basis, i.e. based on the evaluation of energy performance indexes which are calculated over the whole operating year. Indeed, according to the European [2] and the Italian $[5,6]$ regulation, each of the $i$-th cogeneration units has to record the electric energy and useful heat generated during the year and then evaluate its own yearly-basis first principle efficiency ${ }^{1} \eta_{I, i}$, Eq. (1), and Primary Energy Saving index (PES $\left.{ }_{i}\right)$, Eq. (2):

$\eta_{I, i}=\left(\eta_{e l, \operatorname{cog}, i}+\eta_{t h, \operatorname{cog}, i}\right) \geq \widehat{\eta}_{I, i}^{0}$

$\mathrm{PES}_{i}=1-\frac{1}{\left[\frac{\eta_{\text {el,cog, }, i}}{\widehat{\eta}_{\text {el, ref }, i} \cdot p_{i}}+\frac{\eta_{\text {th,cog, }, i}}{\widehat{\eta}_{\text {th,ref }, i}}\right]} \geq \widehat{P E S}_{i}^{0}$.

where the efficiencies $\widehat{\eta}_{e l, \text { ref, }}$ and $\widehat{\eta}_{\text {th,ref }}$, are the reference values for separate electric and thermal power generation, and $p_{i}$ is the factor which keeps into account the grid losses. These values represent the values which are utilized as benchmark to quantify whether there are energy savings; all refer to the national $[5,6]$ and EU legislation [2]. They are unit specific depending on type of fuel and unit age; therefore, they could be different for units belonging to the same pool and especially $\mathrm{p}_{\mathrm{i}}$ is complex to evaluate being dependent on the grid connection voltage as well as on the fraction of electric energy which has been locally consumed or sold to the grid. It is worth pointing out that Eq. (1) and Eq. (2) can be expressed as linear constraints in terms of production and fuel consumption variables (see Section 4.2).

If $\eta_{I, i}$ and $P E S_{i}$ are greater than the given threshold values $\widehat{\eta}_{I, i}^{0}$ and $\widehat{P E S}_{i}^{0}$ (e.g., $\widehat{\eta}_{I, i}^{0}=75 \%$ or $80 \%$ depending on the unit, and $\widehat{P E S}_{i}^{0}=0 \%$ or $10 \%$, depending on the size), the $i$-th cogeneration unit receives cogeneration credits, denoted as $C C_{i}$. These credits are equal to the amount of primary energy saved multiplied by their cost, $c_{c c}$ :

$\left.C C_{i}=\frac{E_{e l, \operatorname{cog}, i}}{\widehat{\eta}_{e l, r e f, i} \cdot p_{i}}+\frac{E_{t h, c o g, i}}{\widehat{\eta}_{t h, r e f, i}}-E_{f u e l, i}\right) \cdot c_{c c}$

Besides, also the costs of natural gas and the prices of electricity typically depend on the total monthly or yearly consumptions. As an example, in Italy [9] excise taxes on natural gas and electricity vary depending on respectively yearly and monthly thresholds of consumption which are reached.

Taking into account cogeneration credits makes the operation planning problem extremely challenging as the whole operating year should be optimized at once imposing the constraints of Eq. (1) and (2). A straightforward extension of the MILP optimization model from weekly to yearly operating horizons would not be

\footnotetext{
${ }^{1}$ Electric and thermal efficiencies of the CHP unit, $\eta_{e l, \operatorname{cog}, i}$ and $\eta_{t h, \operatorname{cog}, i}$, are respectively defined as the electric energy generated (both sold and self-consumed) by the CHP unit $\left(E_{\text {el.cog. } i}\right)$ divided by the fuel energy it consumes $\left(E_{\text {fuel. } i}\right)$ and the useful thermal energy generated (without heat dissipations) by the CHP unit $\left(E_{t h, c o g, i}\right)$ divided by the fuel energy it consumes $\left(E_{f u e l, i}\right)$.
}

viable computationally. Therefore, an ad hoc approach is needed to find close-to-optimal yearly operation schedules in reasonable computational time.

\subsection{Rolling-horizon algorithms}

The basic idea of rolling-horizon algorithms is to split the whole time horizon and operation problem into multiple slots which are solved in sequence as different subproblems. When optimizing the operation of each time slot, the operation in the current time slot is modelled in detail while past and future time slots are taken into account with simplified (also called "aggregate") models. This yields to a considerable saving of computational time while still accounting for the relations between the different time slots. Since beginning of the nineties [10] this group of methods have been utilized in many fields of logistics, chemical, process and energy engineering and several decomposition techniques for its resolution have been developed spanning from time to units and from tasks to resources decomposition and/or aggregations testing different heuristic approaches [11].

Rolling horizon algorithms are typically adopted to solve either operation problems affected by the uncertainty of the input data forecasts or large-scale optimization problems [12]. In the first case, rolling horizon algorithms are used within a model predictive control strategy for the optimal operation, control and scheduling of systems. At each time step, the optimization of the operation is repeated taking into account also future time slots, but only the operating solution for the current time step is implemented. In this way, the data of the optimal operation problem are updated with the current system conditions and the latest (and more accurate) forecasts. In the second class of operation, the scheduling problem is intractable due to the high number of variables; therefore, such time based decomposition techniques are utilized to find a solution that is not guaranteed to be optimal, but yielding a good compromise between computational time and solution quality.

The rolling-horizon approach has been used in many fields to tackle uncertainty ranging from financial studies, where long term interests are pursued without being sure of the future prices [13], to yearly strategies for water management [14]. Other examples are the optimization of reserves with spot market random prices [15], networks of compressors for cryogenic air separation [16], as well as gas markets [17] and the yearly delivery program of liquefied natural gas [18]. Recently rolling horizon algorithms become very important in the operation of energy systems because the optimal operation must account for the uncertainty of weather conditions, consumers' activities and power generation from intermittent renewable energy sources. The rolling-horizon approach is utilized in order to update the load information once it becomes available while optimizing units scheduling, e.g. updated renewable forecast [19] and sophisticated strategies for reducing uncertainty of dispatch adjustment based on joint optimization of unit commitment and reserve policies, adjusted future forecast uncertainty and some binaries relaxation (these not implemented yet while reoptimizing) [20]. Loads and renewables disturbances may arise at different time-scales, thus challenging the frequency stability and bringing to more frequent dispatch with faster time scales [21]. Rolling horizon techniques have been utilized for joint optimization of generation and consumption, when the latter are active consumers [22]. Following this path, more complex studies can be carried on addressing the unit commitment of CHP units integrated with district heating network and heat storage systems [23] as well as combining heat market and both day ahead and balancing electric market where CHP units are considered as a unique virtual power plant together with wind farms [24].

As previously mentioned the rolling-horizon decomposition can 
also be utilized in order to find an approximated solution of realworld problems which are too large to be solved at once. This has also been adopted in different fields of resource task networks [25], going from production scheduling [26] to energy related problems [27] and optimal design and scheduling of energy systems where several days periods need to be tackled [28].

In the presented paper, a rolling-horizon heuristic is developed to optimize the scheduling problem of systems of CHP units with yearly basis constraints on the achievement of cogeneration incentives and monthly fiscal constraints on electricity prices. To the authors' knowledge, this is the first time that such approach has been utilized for such purpose. The presented rolling-horizon method is based on the extension of the multi-period MILP scheduling model proposed in Ref. [8] and it is tested on a real-world case study.

\section{Problem statement}

The operation scheduling problem of combined heat and power plants which can benefit from cogeneration credits can be stated as follows.

Given:

- one and/or two-degree of freedom generation units with fixed size, performance curves, ramp-up and -down rates, and warmup times;

- heat and cooling load storage tank with fixed capacity and constant loss rate;

- time-dependent demands of low and high temperature thermal power;

- time-dependent price of electricity;

- time-dependent ambient temperatures;

- commodities prices based on the achievement of monthly thresholds of electricity consumption and yearly thresholds of natural gas;

- national regulation on cogeneration incentives with minimum required values on the first law efficiency and primary energy saving index of each cogeneration unit (on a yearly basis);

determine for each time period $t$ of a time horizon $T$ :

- the set of units to be switched on;

- the value of the operative variables of each unit;

- the storage tank level;

so as to minimize the operating cost, while satisfying the demands of low and high temperature heat during all the time periods.

The problem constraints can be grouped into the following categories:

a) Balance equations of electricity, high temperature heat, low temperature heat and cooling power (imposing that the customer demands must be satisfied in each time step);

b) maximum and minimum allowed load of each unit;

c) upper limit on the number of start-up per day;

d) energy balance and maximum capacity of the heat storage tanks;

e) periodicity of the storage level (imposing to have the same level at the beginning and end of the time horizon);

f) nonlinear performance curves of the installed units;

g) yearly-basis constraints Eqs. (1) and (2) on the achievement of the cogeneration credits.

It is important to remark that, according to the Italian regulation for cogeneration units [6], all the constraints (g) must be satisfied. Indeed, if the cogeneration unit does not meet one of the constraints ( $\mathrm{g}$ ), the cogeneration credits will be zero (or just related to a smaller part of the consumed fuel ${ }^{2}$ ) and the electric energy generated by the unit will not be prioritized in the electricity market. In other words, the production units have to participate in the electricity market without any guarantee to produce. For this reason, typically plant operators, in order not to lose dispatch priority, want to meet all constraints ( $\mathrm{g}$ ).

\section{Weekly mathematical model description}

Our rolling-horizon method applies to an extension of the Mixed Integer Linear Programming (MILP) model we proposed and extensively described in Ref. [8] for optimizing the daily operational schedule of CCHP systems without cogeneration incentives, constraints $(\mathrm{g})$. Let us recall the model, adjusted for the weekly operational schedule.

\subsection{Sets}

We first introduce the sets used for model characterization because of this set based framework suitability for the implementation in the modeling language. The set T of hours of the week: $T=\{1,2,3,4, \ldots, 168\}$ with the subscript $t$ indicating the variable or parameter corresponding to the $t$-th period of the week. Units were classified according to following criteria:

The useful effect they generate:

- P: set of units which produce electricity,

- HT: set of units which produce high-temperature heat,

- LT: set of units which produce low-temperature heat,

- Cold: set of units which produce cooling load;

The type of energy they utilize and degrees of freedom:

- $I=I_{1} \cup I_{2}$ : set of units which consume fuel (Prime Movers and Auxiliary Boilers):

$I_{1}$ : Subset of units with 1 of freedom,

$I_{2}$ : Subset of units with 2 of freedom,

- El: set of units consuming electricity,

- Th: set of units consuming heat.

Using this classification, units (i.e., cogenerative internal combustion engines, boilers, heat pumps, etc.) can be described in terms of the set(s) to which it belongs.

\subsection{Parameters}

The following parameters have a different value for each time period $t$ being affected by fluctuations of the market prices, energy demands and ambient temperature:

- $\widehat{T}_{0, t}:$ ambient temperature in time period $t$, with $t \in T$,

- $\widehat{e} l_{\mathrm{t}}$ : required electric energy in time period $t$, with $t \in T$,

- $\widehat{q}_{\text {high,t }}$ : required high temperature heat in time period $t$, with $t \in T$,

\footnotetext{
${ }^{2}$ According to the Italian regulation, if the unit cannot meet constraint (g) represented by Eq. (1), a virtual unit could be defined. It is a virtual cogeneration unit smaller than the real one, but capable to fulfill both the constraints of Eqs. (1) and (2). The virtual unit is entitled to receive a fraction of the white certificates (cogeneration incentives) which would be taken by the full unit. In this paper, virtual units have not been included in the model both for sake of simplicity and because the virtual unit is of less practical interest. Indeed, plant operators, in order not to lose dispatch priority, want to meet all constraints $(\mathrm{g})$.
} 
- $\widehat{q}_{\text {low,t }}$ : required low temperature heat in time period $t$, with $t \in T$

- $\widehat{q}_{\text {cold }, t}$ : required cooling load in time period $t$, with $t \in T$,

- $\widehat{c}_{\text {fuel,i,t }}$ : fuel cost for the unit consuming fuel $i$, with $i \in I t \in T$,

- $\widehat{c}_{\text {el,purch,t }}$ : purchased electric energy cost in time period $t$, with $t \in T$,

- $\widehat{c}_{\text {el,sold, }, t}:$ sold electric energy cost in time period $t$, with $t \in T$,

- $\widehat{f}_{\mathrm{i}, \mathrm{t}}^{\mathrm{min}}, \widehat{f}_{\mathrm{i}, \mathrm{t}}^{\mathrm{max}}$ : minimum and maximum limits of consumed fuel for the unit consuming fuel $i$, with $i \in I, t \in T$,

- $\hat{e} l_{\mathrm{i}, \mathrm{t}}^{\min }, \hat{e} l_{\mathrm{i}, \mathrm{t}}^{\max }$ : minimum and maximum limits of consumed electricity for the unit consuming electricity $i$, with $i \in E l, t \in T$,

- $\widehat{q}_{\text {low,i,t }}^{\min }, \widehat{q}_{\text {low,i,t }}^{\max }$ : minimum and maximum limits of consumed low temperature heat for the unit consuming heat $i$, with $i \in T h, t \in T$,

Parameters that are constant are listed below:

- $\widehat{c}_{\text {O\&M,cons,i }}$ operation and maintenance cost proportional to the amount of fuel, heat or electricity utilized by each unit, with $i \in I \cup E l \cup T h$;

- $\widehat{c}_{\mathrm{O} \& \mathrm{M}, \mathrm{time}, \mathrm{i}}$ : operation and maintenance cost proportional to the number of hours each unit is working, with $i \in I \cup E l \cup T h$;

- $\widehat{c}_{O \& M, o n / o f f, i}$ : operation and maintenance cost proportional to the number of start-up operations, with $i \in I \cup E l \cup T h$;

- $\widehat{N}_{\mathrm{i}}$ : maximum number of daily start-ups for each unit, with $i \in I \cup E l \cup T h$;

- $\widehat{c}_{\text {fuel,start,i }}$ : start-up cost proportional to the amount of fuel utilized by each unit, with $i \in I$;

- $\widehat{c}_{\text {el,start,i }}$ : start-up cost proportional to the amount of electricity utilized by each unit, with $i \in($ ElnCold $) \cup(E \ln T h)$;

- $\widehat{c}_{\text {low.start.i }}$ : start-up cost proportional to the amount of low temperature heat utilized by each absorption unit, with $i \in T h$;

- $\widehat{l}_{\text {low,stor,max }}$ : maximum low temperature heat storage level depending on the storage tank size;

- $\widehat{l}_{\text {cold,stor,max }}$ : maximum cooling load storage level depending on the storage tank size;

- $\widehat{u}_{\text {low,los }}$ : low temperature heat storage loss, assumed as a fixed percentage of the hourly heat storage level and depending on the storage tank characteristics like size and thermal insulation.

- $\widehat{u}_{\text {cold,los }}$ : cooling load storage loss, assumed as a fixed percentage of the hourly cooling load storage level and depending on the storage tank characteristics like size and thermal insulation.

- $\widehat{e} l_{a b s, i}$ : amount of electricity consumed by the absorption units per unit of cooling load, with $i \in T h \cup E l \cap$ Cold

\subsection{Continuous (real) variables}

- $f_{\mathrm{i}, \mathrm{t}} \in \mathbb{R}$ : fuel energy input for unit $i$ in time period $t$, with $i \in I$, $t \in T$ and $f_{\mathrm{i}, \mathrm{t}}^{\min } \leq f_{\mathrm{i}, \mathrm{t}} \leq f_{\mathrm{i}, \mathrm{t}}^{\max }$;

- $y_{\mathrm{i}, \mathrm{t}} \in \mathbb{R}$ : the second operative variable, in addition to the fuel consumption, for the units with two degrees of freedom, with $i \in I_{2}, t \in T$ and $0 \leq y_{\mathrm{i}, \mathrm{t}} \leq y_{\mathrm{i}, \mathrm{t}}^{\max }$ with the upper bound $y_{\mathrm{i}, \mathrm{t}}^{\max }$ which may not be constant and depend on the first operative variable;

- $e l_{\mathrm{i}, \mathrm{t}} \in \mathbb{R}$ : electric energy consumed by unit $i$ in time period $t$, with $i \in E l \cup T h, t \in T$ and $\widehat{e} l_{\mathrm{i}, \mathrm{t}}^{\min } \leq e l_{\mathrm{i}, \mathrm{t}} \leq \widehat{e} l_{\mathrm{i}, \mathrm{t}}^{\max }$;

- $q_{\text {low,i,t }} \in \mathbb{R}$ : low temperature heat consumed by the absorption unit $i$ in time period $t$,with $i \in T h, \quad t \in T$ and $\widehat{q}_{\text {low,i,t }}^{\min } \leq q_{\text {low,i,t }} \leq \widehat{q}_{\text {low,i,t }}^{\max }$;
- $e l_{\mathrm{i}, \mathrm{t}} \in \mathbb{R}$ : electric energy generated by prime mover $i$ in time period $t$, with $i \in I, t \in T$ and $e l_{\mathrm{i}, \mathrm{t}} \geq 0$;

- $q_{\text {high,i,t }} \in \mathbb{R}:$ high-temperature thermal energy generated (auxiliary boiler) or cogenerated (prime mover) by the unit $i$ at time $t$, with $i \in I, t \in T$ and $q_{\text {high,i,t }} \geq 0$;

- $q_{\text {low,i,t }} \in \mathbb{R}$ : low temperature thermal energy generated (auxiliary boiler) or cogenerated (prime mover) by the unit $i$ in time period $t$, with $i \in I \cup E l \cup T h, t \in T$ and $q_{\text {low,i,t }} \geq 0$;

- $q_{\text {cold,i,t }} \in \mathbb{R}$ : cooling load generated by the unit $i$ in time period $t$, with $i \in$ EluTh, $t \in T$ and $q_{\text {cold }, \mathrm{i}, \mathrm{t}} \geq 0$;

- $l_{\text {low }, \mathrm{t}} \in \mathbb{R}$ : level of low temperature heat accumulated in the storage tank at the beginning of time period $t$, with $t \in T$;

- $l_{\text {cold }, \mathrm{t}} \in \mathbb{R}$ : level of cooling load accumulated in the storage tank at the beginning of time period $t$, with $t \in T$;

- $q_{\text {deg,t }} \in \mathbb{R}$ : thermal energy degraded from high temperature down to low temperature at time $t$, with $t \in T$ and $q_{\mathrm{deg}, \mathrm{t}} \geq 0$;

- $q_{\text {high, diss,i,t }} \in \mathbb{R}$ : high-temperature thermal energy dissipated by the unit $i$ at time $t$, with $i \in I, t \in T$ and $q_{\text {high,diss,i,t }} \geq 0$;

- $q_{\text {low,diss,i,t }} \in \mathbb{R}$ : low temperature thermal energy dissipated by the unit $i$ in time period $t$, with $i \in I \cup E l, t \in T$ and $q_{\text {low,diss,i.t }} \geq 0$;

- $e l_{\text {purch,t }} \in \mathbb{R}$ : electric energy purchased from the grid in time period $t, t \in T$ and $e l_{\text {purch,t }} \geq 0$;

- $e l_{\text {sold }, t} \in \mathbb{R}$ : electric energy in excess sold to the grid in time period $t$, with $i \in I, t \in T$ and $e l_{\text {sold, } \mathrm{t}} \geq 0$.

\subsection{Binary variables}

- $z_{\mathrm{i}, \mathrm{t}} \in\{0,1\}$ : binary variable describing the on/off status of each unit, with $i \in I \cup E l \cup T h$ and $t \in T$.

- $\Delta_{i, t} \in\{0,1\}$ : binary variable utilized to keep into account whether the unit has been switched on at the beginning of time period $t$, with $i \in I \cup E l \cup T h$ and $t \in T$.

\subsection{Objective function}

The objective function of the original model is the weekly operating cost:

$$
\begin{aligned}
& \sum_{\mathrm{t}=1}^{24 \cdot 7} C_{\mathrm{f}, \text { tot }, \mathrm{t}}+\sum_{\mathrm{t}=1}^{24 \cdot 7} C_{\mathrm{O} \& \mathrm{M}, \mathrm{tot}, \mathrm{t}}+\sum_{\mathrm{t}=1}^{24 \cdot 7} C_{\mathrm{on} / \mathrm{off}, \text { tot }, \mathrm{t}}+\sum_{\mathrm{t}=1}^{24 \cdot 7} E l_{\mathrm{purch}, \mathrm{t}} \\
& -\sum_{\mathrm{t}=1}^{24 \cdot 7} E l_{\text {sold }, \mathrm{t}}
\end{aligned}
$$

where $C_{\mathrm{f}, \text { tot,t }}$ denotes the cost of the total fuel amount consumed by all the units during the $t$ time period, and $C_{O \& M, t o t, t}$ denotes the sum of the operation and maintenance costs of all the units during time $t$. $C_{\text {on/off,tot, } t}$ denotes the total cost of the extra fuel or electric power or heat required by all the units during the $t$ time period in order to start the unit up to production of its useful effect. $E l_{\text {purch,t }}$ denotes the cost of electricity purchased from the grid while $E l_{\text {sold }, t}$ denotes the revenue due to the electricity export to the electric grid during the $t$ time period.

The cost of the fuel consumed in each period $t$ is given by the sum of the amount of fuel each device is utilizing multiplied by its specific cost. Note that the fuel may be different depending on the unit.

$C_{\mathrm{f}, \text { tot }, \mathrm{t}}=\sum_{\mathrm{i} \in \mathrm{I}} \widehat{c}_{\text {fuel,i }} \cdot f_{\mathrm{i}, \mathrm{t}}$ 
The operation and maintenance costs depend on three factors. The first factor is the consumption rate of the units (i.e., the load), and it was assumed to be a linear function of the energy input (fuel, electric power or heat, depending on the unit type). The second factor is the number of operative hours. The third factor takes into account the O\&M penalties related to the start-up operations. As a result, the O\&M costs which will be taken into consideration, are formulated as below:

$$
\begin{aligned}
C_{\text {O\&M tot }, \mathrm{t}}= & \sum_{\mathrm{i} \in \mathrm{I}} \widehat{c}_{\mathrm{O} \& \mathrm{M}, \text { cons }, \mathrm{i}} \cdot f_{\mathrm{i}, \mathrm{t}}+\sum_{\mathrm{i} \in \mathrm{El}} \widehat{c}_{\mathrm{O} \& \mathrm{M}, \text { cons }, \mathrm{i}} \cdot e l_{\mathrm{i}, \mathrm{t}} \\
& +\sum_{\mathrm{i} \in \mathrm{Th}} \widehat{c}_{\mathrm{O} \& \mathrm{M}, \text { cons }, \mathrm{i}} \cdot q_{\text {low }, \mathrm{i}, \mathrm{t}}+\sum_{\mathrm{i} \in \text { IuEluTh }} \widehat{c}_{\text {O\&M,time }, \mathrm{i}} \cdot z_{\mathrm{i}, \mathrm{t}} \\
& +\sum_{\mathrm{i} \in \text { IUEluTh }} \widehat{c}_{\mathrm{O} \& \mathrm{M}, \text { on } / \mathrm{off}, \mathrm{i}} \cdot \Delta_{\mathrm{i}, \mathrm{t}},
\end{aligned}
$$

and the extra cost associated to the start-up procedure, is calculated as in Eq. 7.

$$
\begin{aligned}
C_{\text {on } / \text { off }, \mathrm{t}}= & \sum_{\mathrm{i} \in \mathrm{I}} \widehat{c}_{\text {fuel,start } \mathrm{i}} \cdot \Delta_{\mathrm{i}, \mathrm{t}}+\sum_{\mathrm{i} \in \mathrm{El}} \widehat{c}_{\mathrm{el}, \text { start }, \mathrm{i}} \cdot \Delta_{\mathrm{i}, \mathrm{t}} \\
& +\sum_{\mathrm{i} \in \mathrm{Th}} \widehat{c}_{\text {heat }, \text { start }, \mathrm{i}} \cdot \Delta_{\mathrm{i}, \mathrm{t}} \cdot
\end{aligned}
$$

In Eq. (4), $E l_{\text {purch,t }}$ and $E l_{\text {sold,t }}$ are calculated multiplying the amount of electric energy hourly purchased by the grid, $e l_{\text {purch,t }}$, and sold to the grid, $e l_{\text {sold, } t}$, by the respective price ${ }^{3}$ :

$$
\begin{aligned}
& E l_{\text {purch }, \mathrm{t}}=e l_{\text {purch }, \mathrm{t}} \cdot \widehat{c}_{\mathrm{el}, \text { purch }, \mathrm{t}}, \\
& E l_{\text {sold }, \mathrm{t}}=e l_{\text {sold }, \mathrm{t}} \cdot \widehat{c}_{\mathrm{el}, \text { sold }, \mathrm{t}} .
\end{aligned}
$$

\subsection{Constraints}

Electric energy. The electric energy which is either sold to the grid or bought from the grid at time $t$ is given by the sum of all the electric energy produced by the prime movers at time $t$ (belonging to the set $I$ ) minus the electric energy absorbed by the electrically driven units (belonging to the set $E l$ ), and the electric energy required by the customers $\left(\widehat{e} l_{\mathrm{t}}\right)$.

$e l_{\text {sold }, t}-e l_{\text {purch }, t}=\sum_{i \in P} e l_{i, t}-\sum_{i \in E l} e l_{i, t}-\widehat{e} l_{t}, \forall t \in T$.

Heat and cooling. The constraint on the high temperature thermal power (Eq. (11)) imposes that the customer hightemperature heat requirements need to be fulfilled by the hightemperature heat produced, both considering the cogenerated and not cogenerated (e.g. auxiliary boiler, not cogenerative post firing). If an amount of high-temperature heat larger than required is produced, this can be either wasted via heat exchangers dedicated to dissipate heat $q_{\text {high,diss,i,t }}$ or downgraded to low-temperature heat $q_{\mathrm{deg}, \mathrm{t}}$, as:

$\sum_{\mathrm{i} \in \mathrm{I}} q_{\mathrm{high}, \mathrm{i}, \mathrm{t}}-\sum_{\mathrm{i} \in \mathrm{I}} q_{\text {high,diss,i,t }}-q_{\mathrm{deg}, \mathrm{t}}=\widehat{q}_{\text {high,t }}, \forall t \in T$.

The constraint on the low temperature thermal power (Eq. (12)) ensures that customer requirements of low-temperature heat are

\footnotetext{
${ }^{3}$ This formulation implies that the selling price should always be lower than the purchase price.
}

always fulfilled by both cogenerated and not cogenerated heat (e.g. auxiliary boiler, not cogenerative post firing), together with the extra high-temperature heat available at low temperature after a downgrade. Low-temperature heat can also be consumed by absorption units. In addition, the thermal storage can be used either to fulfill the customer requirements, in case heat has been previously accumulated, or it can be filled with heat, when the lowtemperature heat production exceeds the customer requirements for that specific hour, $t$. Furthermore excess heat can be dissipated in the environment via dedicated heat exchangers, $q_{\text {low,diss,i,t }}$. Such logic is formulated with the following constraint:

$$
\begin{aligned}
\sum_{\mathrm{i} \in \mathrm{I} \cup \mathrm{El}} q_{\text {low }, \mathrm{i}, \mathrm{t}} & -\sum_{\mathrm{i} \in \mathrm{Th}} q_{\text {low }, \mathrm{i}, \mathrm{t}}-\sum_{\mathrm{i} \in \mathrm{I \cup El}} q_{\text {low }, \mathrm{diss}, \mathrm{i}, \mathrm{t}}+q_{\mathrm{deg}, \mathrm{t}} \\
& +\left(l_{\text {low }, \mathrm{t}}-l_{\text {low }, \mathrm{t}+1}\right)-l_{\text {low }, \mathrm{t}} \cdot \widehat{u}_{\text {low }, \text { los }}=\widehat{q}_{\text {low }, \mathrm{t}}, \quad \forall t \in T .
\end{aligned}
$$

In the proposed formulation, it is important to quantify the dissipation of each unit because it is necessary to calculate $\eta_{I, i}$ and $P E S_{i}$ (Eqs. (1) and (2)) respectively) for each CHP engine. Indeed, the dissipated heat actually reduces the value of $E_{t h, c o g}$ and consequently the value of $\eta_{t h, c o g}$.

The level of accumulated heat has to be non-negative and not larger than the maximum storage value allowed (Eqs. (13) and (14)):

$l_{\text {low }, \mathrm{t}} \geq 0, \forall t \in T$,

$l_{\text {low,t }} \leq \widehat{l}_{\text {low,max }}, \forall t \in T$.

Similarly to the HT and LT heat, also the cooling load balance has to be always fulfilled (Eq. (15)). The generated cooling load, both by compression and absorption units, needs to fulfill the customer requirements for each hour $t$. Thermal storage can be used with the same logic of the low temperature heat balance:

$$
\sum_{\mathrm{i} \in \text { Cold }} q_{\text {cold }, \mathrm{i}, \mathrm{t}}+\left(l_{\text {cold }, t}-l_{\text {cold }, t+1}\right)-l_{\text {cold }, t} \cdot \widehat{u}_{\text {cold }, l o s} \geq \widehat{q}_{\text {cold }, \mathrm{t}}, \forall t \in T .
$$

Both for low-temperature heat and the cooling load, the level of thermal storage at the end of the day must be equal to that at the beginning of the day.

Technical limits. Each unit has a minimum and maximum value of electric energy (Eq. (16)), high temperature heat (Eq. (17)), low temperature heat and cooling load it can produce in each hour (Eqs. (18) and (19)). These technical limits are imposed by the following constraints, which also impose the values of electric and thermal power being zero in case the device is shut down, thanks to binary variables $z_{\mathrm{i}, \mathrm{t}}$ :

$$
\begin{aligned}
z_{\mathrm{i}, \mathrm{t}} \cdot \widehat{e} l_{\text {min,i,t }} \leq e l_{\mathrm{i}, \mathrm{t}} \leq z_{\mathrm{i}, \mathrm{t}} \cdot \widehat{e} l_{\text {max,i,t }}, \text { with, } \quad i \in I, \text { and } \forall t \in T, \\
\begin{aligned}
& z_{\mathrm{i}, \mathrm{t}} \cdot \widehat{q}_{\text {high,min,i,t }} \leq q_{\text {high,i,t }} \leq z_{\mathrm{i}, \mathrm{t}} \cdot \widehat{q}_{\text {high,max,i,t }} \\
& \text {, with } i \in I \cup E l \text { and } \forall t \in T, \\
& z_{\mathrm{i}, \mathrm{t}} \cdot \widehat{q}_{\text {low,min,i,t }} \leq q_{\text {low,i,t }} \leq z_{\mathrm{i}, \mathrm{t}} \cdot \widehat{q}_{\text {low,max,i,t }}, \\
& \text { with } i \in I \cup E l \text { and } \forall t \in T,
\end{aligned}
\end{aligned}
$$

$$
z_{\mathrm{i}, \mathrm{t}} \cdot \widehat{q}_{\text {cold, min,i,t }} \leq q_{\text {cold }, \mathrm{i}, \mathrm{t}} \leq z_{\mathrm{i}, \mathrm{t}} \cdot \widehat{q}_{\text {cold, max }, \mathrm{i}, \mathrm{t}},
$$$$
\text { with } i \in \text { Cold and } \forall t \in T \text {. }
$$

Start-ups. The "start-up" constraints are used in order to set a 
maximum number of start-up procedures that can be tolerated by each process unit on a daily basis, in order to avoid damages. These values depend on the characteristics of each single unit (Eq. (20)).

$\sum_{\mathrm{T}} \Delta_{\mathrm{i}, \mathrm{t}} \leq \widehat{N}_{\mathrm{s}, \mathrm{i}}$, with $i \in \mathrm{I} \cup$ ElUTh.

To ensure that the variable $\Delta_{\mathrm{i}, \mathrm{t}}$ has value 1 at time $t$ if, and only if, unit $i$ was off at time $t-1\left(z_{\mathrm{i}, \mathrm{t}-1}=0\right)$ and is on at time $t$, we introduce the following constraints for each $i \in I \cup E l \cup T h$ and $t \in T$ (Eq. (21)-(23)):

$\Delta_{\mathrm{i}, \mathrm{t}} \geq z_{\mathrm{i}, \mathrm{t}}-z_{\mathrm{i}, \mathrm{t}-1}$

$\Delta_{\mathrm{i}, \mathrm{t}} \leq 1-z_{\mathrm{i}, \mathrm{t}-1}$

$\Delta_{\mathrm{i}, \mathrm{t}} \geq z_{\mathrm{i}, \mathrm{t}}$

Note that we impose that at the end of the day, the state of the system has to be exactly the same as the beginning of the day. Therefore, for $t=1$, the previous time period $(t-1)$ is to be considered $t=24$.

\subsection{Linearization of performance maps}

For each unit of the system, the input variables (consumed fuel and electricity) are related to the output variables (generated heat, electricity, cooling) by means of the performance curves $g_{i, t}$, which have been computed by carrying out a polynomial regression of the available data provided by the manufacturers. The following general performance curves are considered for each type of unit:

- Heat pumps, $i \in E \ln L T$

- $q_{\text {low }, i, t}=g_{i, t}\left(e l_{i, t}\right)$

- Low-temperature auxiliary boilers, $i \in I_{1} \cap L T$

- $q_{\text {low }, i, t}=g_{i, t}\left(f_{i, t}\right)$

- High-temperature auxiliary boilers, $i \in I_{1} \cap H T$

- $q_{\text {high }, i, t}=g_{i, t}\left(f_{i, t}\right)$

- Prime movers with one degree of freedom (e.g. internal combustion engines and gas turbines without post-firing), $i \in I_{1} \cap H T \cap L T \cap E l$

- $q_{\text {low }, i, t}=g_{i, t}^{\prime}\left(f_{i, t}\right)$

- $q_{\text {high }, i, t}=g_{i, t}^{\prime \prime}\left(f_{i, t}\right)$

- $e l_{i, t}=g_{i, t}^{\prime \prime \prime}\left(f_{i, t}\right)$

- Prime movers with two degrees of freedom (e.g. gas turbines with post-firing), $i \in I_{2} \cap H T \cap L T \cap P$

- $q_{\text {low }, i, t}=g_{i, t}^{\prime}\left(f_{i, t}, y_{i, t}\right)$

- $q_{\text {high,i,t }}=g_{i, t}^{\prime \prime}\left(f_{i, t}, y_{i, t}\right)$

- $e l_{i, t}=g_{i, t}^{\prime \prime \prime}\left(f_{i, t}, y_{i, t}\right)$

- Compression chillers, $i \in$ ElnCold

- $q_{\text {cold }, i, t}=g_{i, t}\left(e l_{i, t}\right)$

- Absorption chillers, $i \in$ ThกElnCold.

- $q_{\text {cold }, i, t}=g_{i, t}\left(q_{\text {low }, i, t}\right)$

The nonlinear performance curves of the generation units are approximated by using PieceWise Linear (PWL) functions according to state-of-the-art techniques, see e.g. Ref. [29]. The PWL approximations could deal with non-smooth functions and yield

\footnotetext{
${ }^{4}$ The MILP gap is computed as the (normalized) difference between the value of the best solution and the best lower bound found by CPLEX. This clearly provides an upper bound on the actual distance from optimality.
}

accurate estimates of the optimal objective function values already with 10 interval approximations. Computational results show that close-to-optimal solutions (relative MILP gap ${ }^{4}$ 9E-3\%) can be found in short computational times (at most $5 \mathrm{~min}$ ) even for challenging networks of units. The model has been extensively tested and qualitatively validated versus heuristic models [30,31] as well as non linear formulations [32].

When trying to account for the annual cogeneration incentives, the main challenge is the excessive computational requirements to tackle yearly MILP formulations with state-of-the-art solvers such as CPLEX [33]. If, for example, the MILP model is applied to the optimization of a single week $(24 \times 7$ periods), the number of variables (both integer and real) and constraints already increases by a factor of 7 compared to a the daily problem. Looking at the test case presented in the upcoming Sections, the model for the daily operation problem has 864 integer variables, 1944 real variables and 2863 constraints while that for the weekly operation problem has 6048,13608 and 20035 respectively. Setting a gap of $0.1 \%$ on the MILP solution, the optimization of the daily operation problem takes tens of seconds while the weekly problem may take even thousands of seconds. This indicates that it is clearly impractical to extend the time horizon of the MILP formulation from 7 to 365 days (it is worth noting that the yearly problems could easily feature the order of magnitude of one hundred thousand binary variables and one million continuous variables).

\section{Rolling-horizon optimization algorithm}

This Section describse the ad-hoc rolling-horizon heuristic algorithm devised to optimize the scheduling with yearly-basis incentive constraints. The idea is to subdivide the overall problem into a sequence of smaller subproblems, i.e., weekly scheduling problems, and optimize each subproblem in sequence including aggregate information for the other periods.

\subsection{Extended MILP model}

The basic building block of the algorithm is the MILP formulation that is used to model in detail a weekly operational planning problem. The formulation is based on the daily MILP model we proposed in [8], that is extended in Chapter 3 to optimize a whole week of operation.

Observe that, if the system includes heat storage, it is important to consider reasonably long time horizons to fully exploit the storage system. However, a longer time horizon $T$ means a larger size (and complexity) of the MILP to be solved. For the heat storage systems typically used in industrial and residential applications, the time horizon $T$ of one week appears to be a reasonable compromise between computational complexity and solution quality. Besides, the weekly horizon has the advantage of coinciding with the typical periodicity of the heat demand profile and electricity prices. Although significantly increased with respect to the daily problem, the computational time needed for a whole week $(24 \times 7$ periods) is acceptable and allows for the use of the MILP model within the algorithm.

Compared to the MILP model presented in [8], the modified MILP model also includes:

1) extra variables for each unit in order to quantify the thermal power which is actually supplied to the end user (which is taken into account in the calculation of the plant thermal efficiency, first law efficiency and PES); this allows to determine the thermal power generated by each unit which is dissipated; 
2) yearly-basis constraints, Eq. (1) and Eq. (2), on the minimum values of the performance indicators required to obtain the incentives;

3) a different objective function which keeps into account of revenues from primary energy saving and fiscal terms:

$$
\begin{aligned}
\sum_{t=1}^{24 \cdot 7} C_{f, t o t, t} & +\sum_{t=1}^{24 \cdot 7} C_{O \& M, t o t, t}+\sum_{t=1}^{24 \cdot 7} C_{o n / o f f, t o t, t}+\sum_{t=1}^{24 \cdot 7} E l_{\text {purch }, t} \\
& -\sum_{t=1}^{24 \cdot 7} E l_{\text {sold }, t}+\sum_{t=1}^{24 \cdot 7} E x_{h, t}+E x_{\text {forf }}-\text { Inc }
\end{aligned}
$$

In Eq. (4), the first three terms represent the cost of fuel, operations and maintenance (O\&M) and startup/shutdown. $E x_{\mathrm{h}, t}$ denotes the hourly excise which needs to be paid per kWh of electricity consumed, both purchased and cogenerated. In fact, according to the Italian legislation [9], the consumed electricity needs to pay an excise, no matter whether it is self-produced or purchased. If the electricity consumption is above a certain threshold, the excise is no longer applicable on an hourly basis, and is replaced by a monthly forfeit. For simplicity, we split this monthly forfeit to derive a weekly one, $E x_{\text {forf }}$. The last term, Inc, represents the so-called white certificates equal to the summation of the cogeneration credits $C C_{i}$, Eq. (3), per all the cogenerative units and weekly time period. Gas price depends on yearly thresholds according to the Italian legislation [9]. For all the excises and prices depending on thresholds values, a reasonable guess is made and then it is verified and updated after each rolling horizon loop (spanning the whole year).

Note that constraints Eq. (1) and Eq. (2) concern the whole year, since they involve efficiencies that are computed with the cogenerated heat and electricity, and consumed fuel, of each week of the year. Then, even in the optimization of the operation scheduling of a single week, we must take into account the contribution of all the other weeks of the year.

\subsection{Description of the algorithm}

The block-flow diagram of the algorithm is shown in Fig. 1 and its pseudo-code is reported in Fig. 2.

First, in the initialization step (described in Sub-Section 4.2.1), the load input data are processed, a few typical weeks representative of the whole year are defined and their scheduling is optimized. Then, the iterative procedure is started. In the first rollinghorizon loop, the whole year is optimized utilizing the typical weeks' results to forecast the future energy consumptions (see SubSection 4.2.3). Afterwards, a second rolling horizon loop is performed using the results of the previous $\mathrm{RH}$ loop to accurately estimate the future energy consumptions (see Sub-Section 4.2.4). If at the end of the second rolling horizon loop the yearly constraints on the incentives are not satisfied (due to a too optimistic estimate of the future energy consumptions), the estimate for the future energy consumption is increased and the $\mathrm{RH}$ loop is repeated. It is worth noting that the use of the typical weeks in the initialization step yields an optimistic estimate of the energy consumption (see the motivation in Sub-Section 4.2.1) which is progressively increased across the $\mathrm{RH}$ loops.

\subsubsection{Initialization: estimating the energy consumption of the typical weeks}

The use of a set of typical periods for representing a year provides an efficient method for decreasing the number of data describing the energy demand profile, and consequently the number of parameters, variables and constraints of the multiperiod optimization model. We assume that a year, as well as its portions, can be approximated by a properly defined set of few representative periods. This approach has already been exploited by Fazlollahi et al., 2014 [34], Dominguez-Munoz et al., 2011 [35], Elsido et al. [36] which used the "k-means algorithm" [37] to determine the typical periods (days, weeks) for the optimal design of CHP systems and networks.

The problem for the selection of the typical weeks can be stated as reported below.

Given:

- the expected hourly profiles of heat and electricity demands over a time horizon of the future weeks of the year $(i+1, \ldots, 52)$, derived from historical data;

- the expected hourly profiles of ambient temperature of the installation site over the future weeks of the year $(i+1, \ldots, 52)$, derived from historical data;

The k-means algorithm determines a set of $N w$ representative weekly periods, and in particular:

- partition the future weeks of the year $(i+1, \ldots, 52)$ in $N w$ clusters, each represented by one typical week;

- determine the representative hourly profiles of heat and electricity demands of each typical week;

- determine the representative hourly profiles of ambient temperature of the installation site of each typical week,

so as to minimize the overall within-cluster distances (i.e., the sum of the distances between each original week and its typical week in all clusters).

In this work, the typical weeks are used so as to estimate the primary energy consumption and energy production of the CHP units in the future weeks $(i+1, \ldots, 52)$ under the incentive constraints. Indeed, the $\mathrm{k}$-means algorithm partitions the future weeks in clusters, each one represented by an average typical week. Thus, it allows to associate each week of the year with the most representative typical week, as shown in Fig. 3.

Moreover, since the heat load profiles of future weeks can be replaced by those of the associated typical weeks, the whole year can be represented as a proper combination of typical weeks. In the example of Fig. 3, the year can be represented as a sequence of the three typical weeks using 17 typical weeks of type 1,17 of type 2 and 18 of type 3 . Keeping this simplified representation of the year

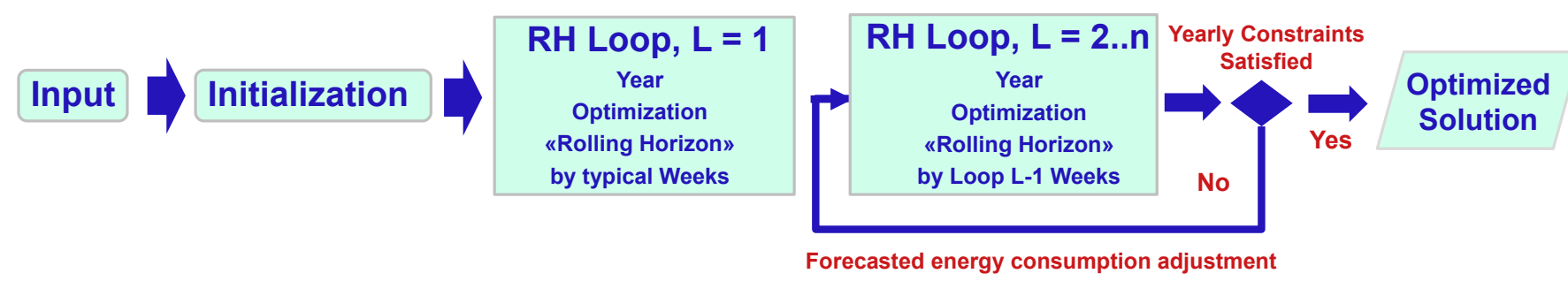

Fig. 1. Block-flow diagram of the rolling-horizon algorithm. 


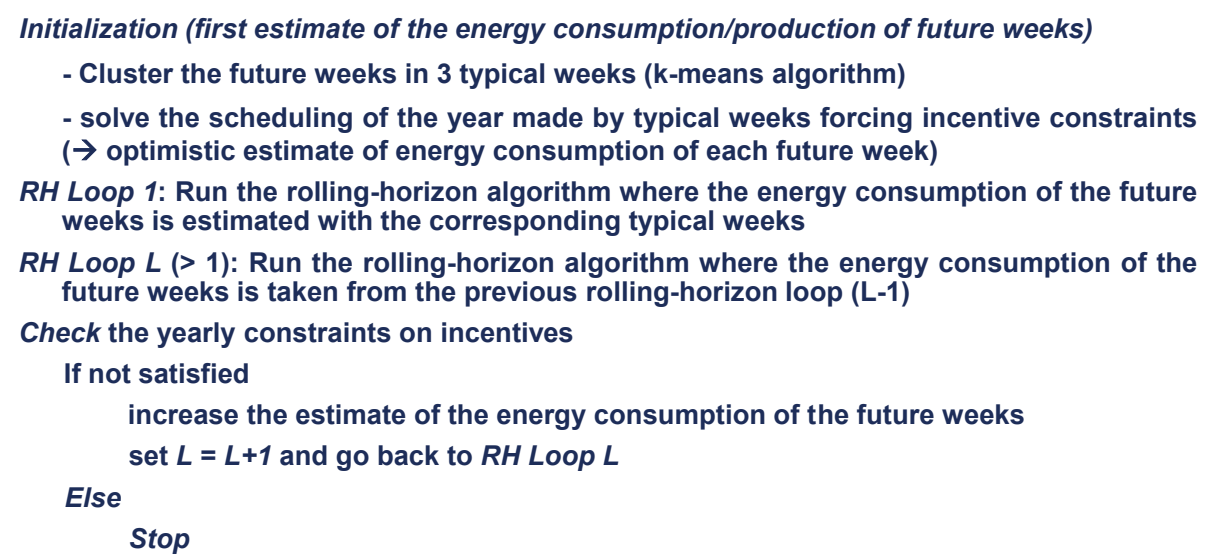

Fig. 2. Pseudo-code of the rolling-horizon algorithm.

(or just for the future weeks of the year), it is possible to optimize the scheduling of the three typical weeks in a single MILP which covers the whole year and include the yearly basis constraints, Eq. (1) and Eq. (2). For the test case reported in Section 4, the scheduling MILP features about 18000 binary variables 40000 real variables, 60000 constraints (corresponding to the sum of scheduling variables and constraints of the three typical weeks plus the incentive-related constraints) and its solution to a MILP gap below $0.1 \%$ takes a computational time of about $15 \mathrm{~min}$.

The output of the initialization step can be used as first estimate of the primary energy consumption and energy production of the CHP units for each future week of the year, utilizing for each future week the results of the optimized typical week belonging to the same set. It is worth noting that such an estimate of energy consumption is typically optimistic because the energy demand profiles of the typical weeks are smoother, with lower peaks, than the actual profiles. The reason is the fact that the profiles of the typical weeks are obtained as averages of the profiles of the actual weeks of the cluster.

\subsubsection{Rolling-Horizon ( $R H$ ) loop}

The rolling horizon loop structure is shown in Fig. 4. Let us assume that we are at the end of the $i$-th week of the year, so the energy consumption and efficiency values of the cogeneration units over the past weeks $1, i$ are known. Our aim is determining the optimal schedule for the future weeks $i+1, \ldots, 52$, while satisfying the annual incentive constraints, Eq. (1), and Eq. (2). The rollinghorizon algorithm consists in solving a sequence of weekly MILP sub problems (described in Section 3), corresponding to the weeks $k=i+1, \ldots, 52$. In Fig. 4 the algorithm is shown in three different steps: (i) when optimizing the week $k$ immediately after the current week, labeled with $k=i+1$; (ii) when optimizing a future week $k$ in the middle of the year, with $k>i+1$ and $<52$; (iii) when optimizing the last week of the year, denoted with $k=52$.

\subsubsection{First loop: solving weekly subproblems with aggregated} estimates from typical weeks

In the first phase, we solve sequentially the subproblem $k$, with $k=i+1, \ldots, 52$, (from the next week to the end of the year) to get a starting solution. When solving the $k$-th weekly subproblem, in the global constraints, Eq. (1) and Eq. (2), the variables corresponding to week $k$ have to be optimized, while the values of the variables corresponding to the weeks $1, \ldots, k-1$ are already known (either because these are past weeks of the year or because their scheduling has been already optimized in the rolling-horizon loop), and aggregated estimates of the contribution of the future weeks $k+1$, ..., 52 not yet optimized are considered. In particular, to estimate the contribution of the future weeks not yet passed or optimized $(k+1, \ldots, 52)$, we use the results of the "typical weeks" previously determined. Since each week has been associated to a typical week set in the initialization step, the energy consumption and energy production of the CHP units (heat and electricity relevant to the global constraints Eq. (1) and Eq. (2)) of the future weeks $(k+1, \ldots$, 52) can be reasonably approximated by looking at those of the associated typical weeks.

Clearly the solution obtained using estimates based on the "typical weeks" does not necessarily satisfy the yearly-basis constraints because the estimate of the primary energy consumption of the typical weeks may be too optimistic due to the efficiency constraints imposed in the initialization step. In addition, the actual load profiles may have profiles significantly different and featuring larger load variations that those of the typical weeks, and this may significantly underestimate the efficiency penalties occurring in on/ off operations of the CHP units. For these reasons, the yearly scheduling solution obtained at the end of the first loop must be revised.

\subsubsection{Second phase: iteratively solving weekly subproblems with aggregated estimates from previous solutions}

At each iteration of the second phase we repeat the rollinghorizon algorithm by solving a $k$-th weekly subproblem for all the weeks with $k=i+1, \ldots, 52$. Here, in the $k$-th weekly subproblem, we consider as an estimate of the contributions of the weeks $k+1, \ldots$, 52 the results (operation schedules) obtained in the previous iteration. At the end of each iteration, that is, after the $52^{\text {nd }}$ subproblem has been solved, we need to recompute the incentives (e.g., the

\begin{tabular}{|c|c|c|c|c|c|c|c|c|c|c|c|c|c|c|c|c|c|c|c|c|c|c|c|c|}
\hline 1 & 2 & 3 & 4 & 5 & 6 & 7 & 8 & 9 & 10 & 11 & 12 & 13 & 14 & 15 & 16 & 17 & 18 & 19 & 20 & 21 & 22 & 23 & 2425 & 26 \\
\hline 1 & 1 & 1 & 1 & 1 & 1 & 1 & 1 & 1 & 2 & 2 & 2 & 2 & 2 & 2 & 2 & 2 & 2 & 2 & 2 & 2 & 3 & 3 & 3 & 3 \\
\hline 27 & 28 & 29 & 30 & 31 & 32 & 33 & 34 & 35 & 36 & 37 & 38 & 39 & 40 & 41 & 42 & 43 & 44 & 45 & 46 & 47 & 48 & 49 & \begin{tabular}{l|l}
50 & 51
\end{tabular} & 52 \\
\hline 3 & 3 & 3 & 3 & 3 & 3 & 3 & 3 & 3 & 3 & 3 & 3 & 3 & 2 & 2 & 2 & 2 & 2 & 1 & 1 & 1 & 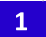 & 1 & 1 & 1 \\
\hline
\end{tabular}

Fig. 3. Example of assignments weeks - typical weeks (colored lines) found by the k-means algorithm. 

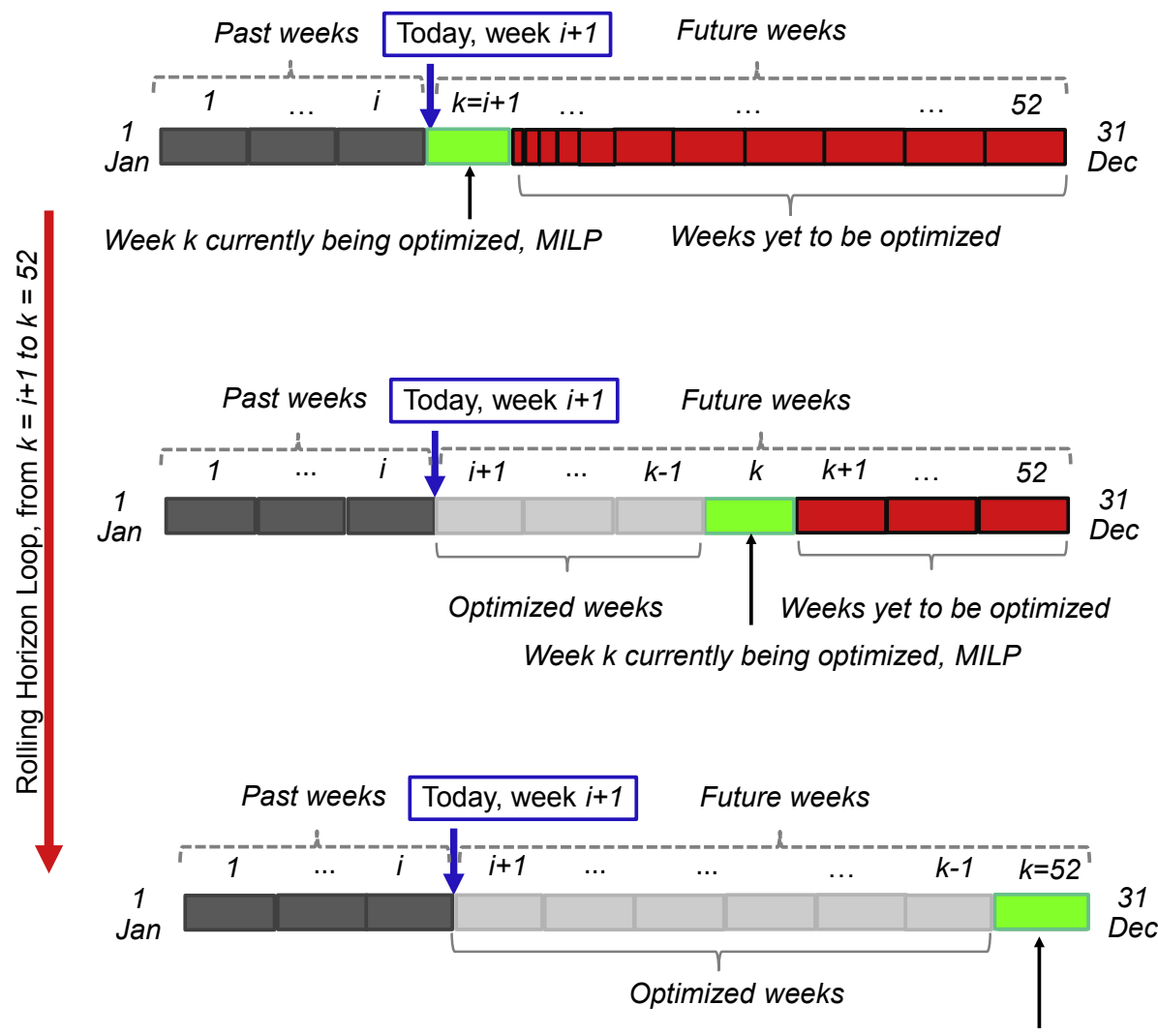

Week $k$ currently being optimized, MILP

Fig. 4. Schematic representation of the rolling horizon loop starting in week $i+1$ and running till the end of the year.

credits according to Eq. (3)) on the basis of the obtained solution. The second phase iterations allow to improve the quality of the estimates of the contributions in Eq. (1) and Eq. (2) of the future weeks $(k+1, \ldots, 52)$. The $\mathrm{RH}$ Loop algorithm is repeated until the value of the objective function (total annual operating cost) remains constant across the iterations. In practice, we have observed that this typically occurs after few iterations.

Note that, if Eq. (1) and Eq. (2) are not satisfied, the rollinghorizon algorithm must be repeated trying to force constraints related to Eq. (1) and Eq. (2) for all the cogeneration units. Infeasibilities with respect to Eq. (1) and Eq. (2) may arise when the estimate of the contribution of the weeks yet to be optimized is too optimistic in terms of energy consumption and efficiency of the cogeneration units. In this case, earlier weeks of the year would be optimized mainly for the minimum operating cost, since the annual constraints appear to be easy to satisfy in the future. Such a schedule, especially for the weeks with high electricity prices and low thermal loads, has a poor PES index and efficiencies as it tends to run the cogeneration units at full load wasting thermal power (i.e., like an electric power plant). Thus Eq. (1) and Eq. (2) may not be satisfied at the end of the year. This can be avoided by increasing the estimate of primary energy consumption of the cogeneration units in the future weeks, so as to mitigate the effects of overoptimistic estimates and find a more conservative schedule satisfying Eq. (1) and Eq. (2).

It is also worth noting that solving the weekly MILP subproblems is usually much faster in the second phase than in the first phase. Indeed, to solve any $k$-th weekly subproblem, we can use the "warm start" option of the MILP solver giving as starting point the solution obtained in the previous iteration (which is usually quite close to the subproblem optimal solution).

\section{Test case}

A schematic representation of the heat and power distribution network considered for the test case is shown in Fig. 5. It is based on an existing hospital distribution system composed of three networks designed for the electric energy (el), high and low temperature thermal energy ( $\mathrm{q}_{\text {high }}$ and $\mathrm{q}_{\text {low }}$ ). The High Temperature (HT) heat network represents the steam demand e.g. for sterilization purposes, while the Low Temperature (LT) heat network models the district heating network. Finally, the heat dissipated by each unit $\left(\mathrm{q}_{\text {diss }}\right)$ has been included in the model.

The considered electric and thermal loads were derived from an accurate reconstruction of real measured data, so they are different through the whole year. For the sake of simplicity, Fig. 6 shows LT heat, HT heat, and electricity daily user's demands for three average weeks together with ambient temperature profiles. Fig. 6a) and b) and c) show the winter, mid-season and summer season, respectively. On the left side (Figs. 6 and 1), the working days (i.e. Monday) are reported, while on the right side (Figs. 6 and 2) the non-working days (Sunday). Fig. 7 shows the annual load duration curve of the ambient temperature and the energy demands, highlighting their yearly variability.

HT heat demand corresponds to steam at $134{ }^{\circ} \mathrm{C}$ used for sterilization purposes. It has a flat hourly profile and is requested only during day hours. The corresponding load duration curve (Fig. 7, c) does not have a smooth profile but reflects an on-off operating strategy. The LT demand shows a significant yearly variation (around a factor of five) as consequence of the room heating demand as in Fig. 7, d); under this term both the domestic hot water and hot water for space heating are taken into account at temperatures respectively of $50-60^{\circ} \mathrm{C}$ and $70^{\circ} \mathrm{C}$. The electric demand is 


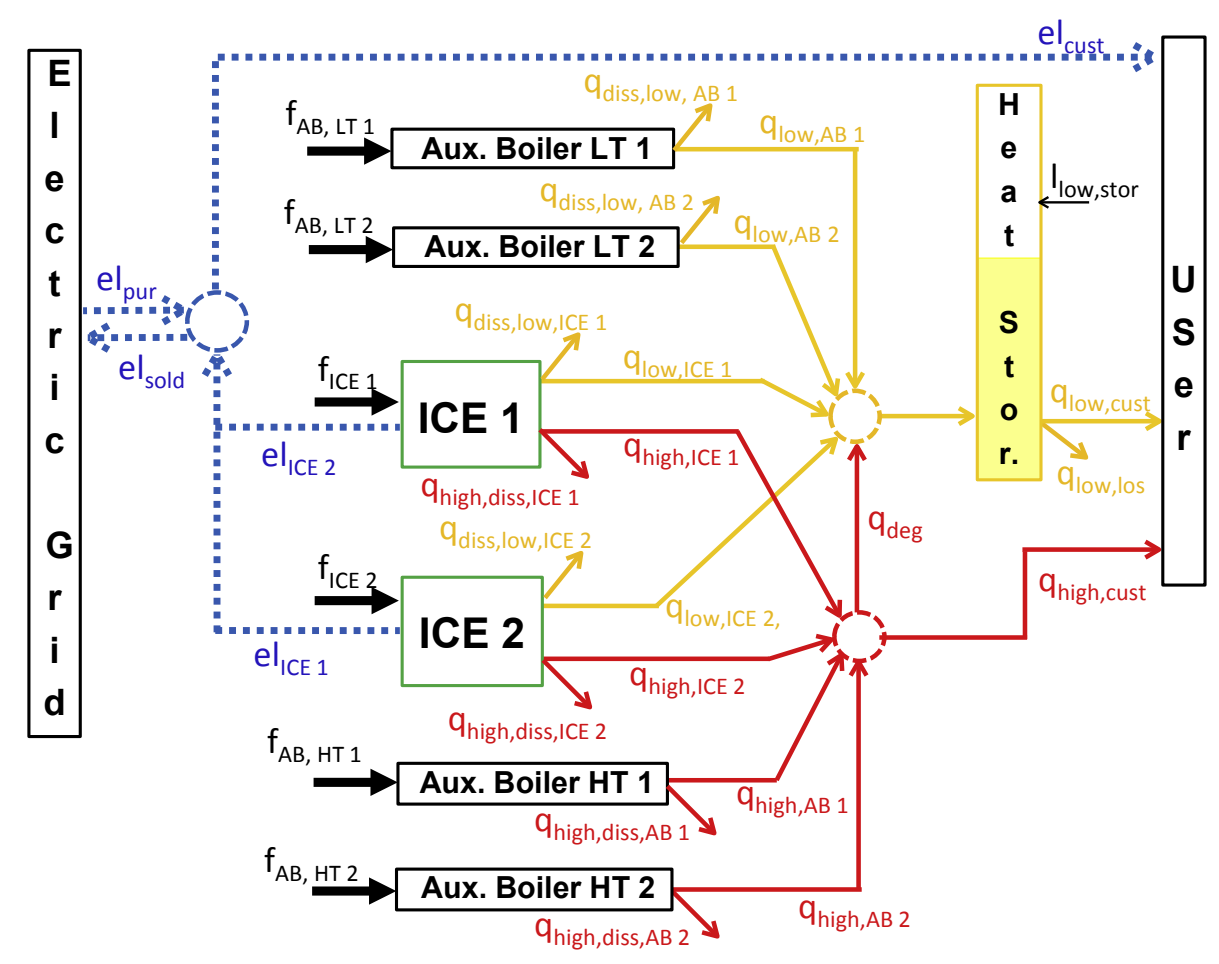

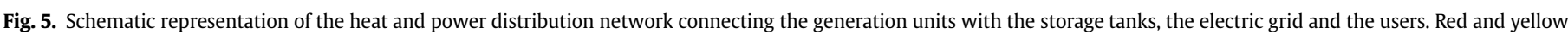

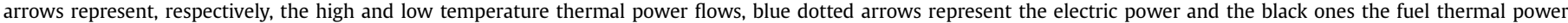
consumed by each unit. (For interpretation of the references to colour in this figure legend, the reader is referred to the web version of this article.)

higher during day time, because of ambulatory activities, and in summer, because of the air conditioning which is made by electric chillers. For each season, a significant difference in loads between week and week end days can be observed because of ambulatory services are performed only from Monday to Friday.

The electricity and thermal demand of the hospital is supplied by two internal combustion engines (ICE) as prime movers, two auxiliary boilers $(\mathrm{AB})$ at HT and two at LT. The engine performance curves as function of the load (a) and ambient temperature (b) are shown in Fig. 8. Heat is recovered from the intercooler, then from the oil circuit (which is at $75-80^{\circ} \mathrm{C}$ ), from the engine cooling water at $80-100^{\circ} \mathrm{C}$, and finally from the engine exhausts which leave the engine at about $400{ }^{\circ} \mathrm{C}$. The thermal power from the oil circuit, cooling water and intercooler are recovered as LT heat, while that from the exhaust gases as HT heat. In Fig. 8, c), the non-dimensional characteristic curves of the auxiliary boilers as func-tion of the load are presented. No significant differences can be outlined between HT and LT, while the nominal values are re-ported in Table 1.

Finally, economic assumptions considered in this analysis are summarized in Table 2. About electricity prices, they are taken from the Italian electric market which divides the day in three different slots corresponding to high peak (9-19 h), base (24-7 h) and intermediate hours (7-9 $\mathrm{h}$ and 19-24 h). The Reverse-MeteringFactor ${ }^{5}$ (RMF) depends as well on the hour of the day. Peak hours show the lowest RMF. In order to show the effectiveness of the proposed rolling horizon algorithm and the impact of the cogeneration incentives on the optimal operation strategy of the engines, five different scenarios have been considered:

\footnotetext{
5 The Reverse-Metering-Factor is defined as the ratio between the sale and the purchased price of electricity.
}

- S1, the system without thermal storage with operation strategy optimized using the rolling horizon algorithm proposed in this work so as to obtain the cogeneration incentives,

- S2, the system without thermal storage operated with operation strategy optimized on a weekly basis with the MILP model described in Section 3 without including neither the constraints on first law efficiency and primary saving index nor cogeneration incentives,

- S3, the system with thermal storage operated with the rolling horizon algorithm so as to obtain the cogeneration incentives,

- S4, the system without thermal storage with operation optimized on a weekly basis with the MILP model described in Section 3 including the constraints on first law efficiency and primary saving index. This case obtains the cogeneration incentives, but the scheduling is more conservative than case S1 because efficiency constraints are imposed on each week of the year,

- S5, the system with thermal storage with operation optimized on a weekly basis with the MILP model described in Section 3 including the constraints on first law efficiency and primary saving index. This case obtains the cogeneration incentives, but the scheduling should be more conservative than case S3 because efficiency constraints are imposed on each week of the year.

The thermal storage system has a capacity of $12,000 \mathrm{kWh}_{\text {th }}$ (low temperature heat).

\section{Results}

This Section summarizes the optimization results for the three considered scenarios. Results refer to the sixth iteration $(n=6)$ in the overall algorithm described in Section 4, applied to the whole year, from week $1-52$. 
a,1)

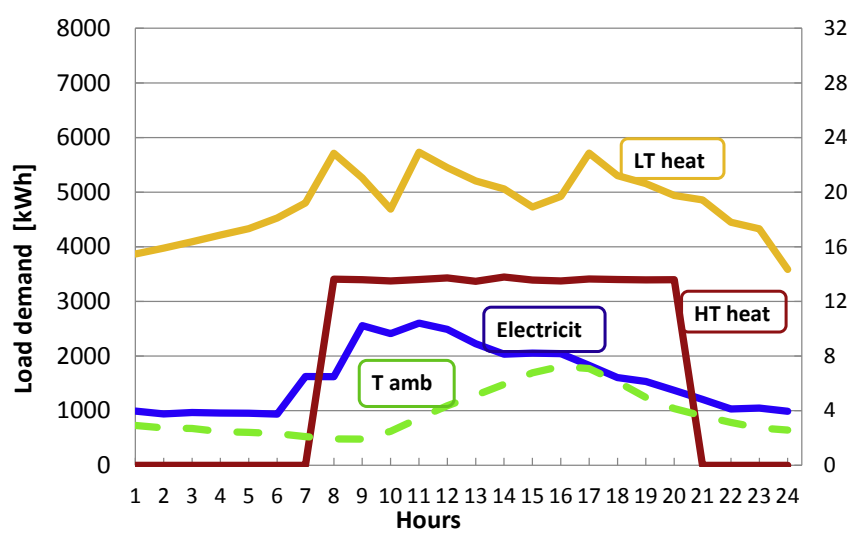

b, 1)

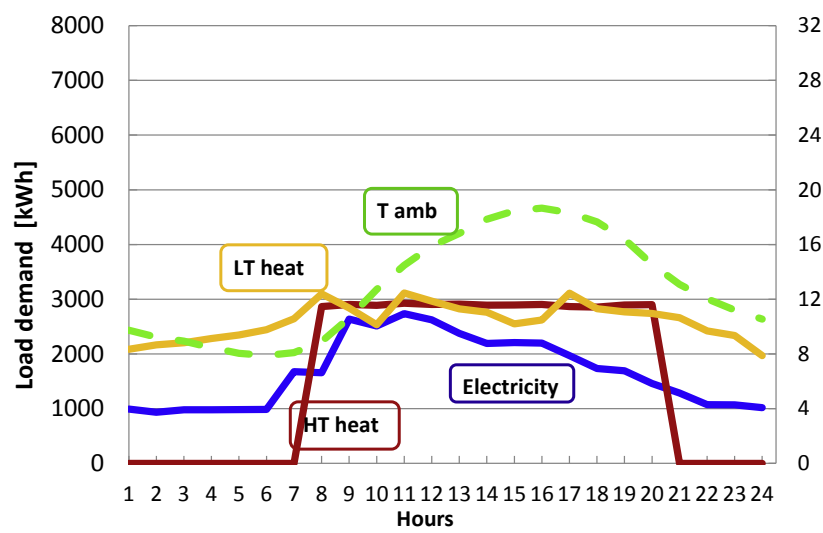

$\mathrm{c}, 1)$

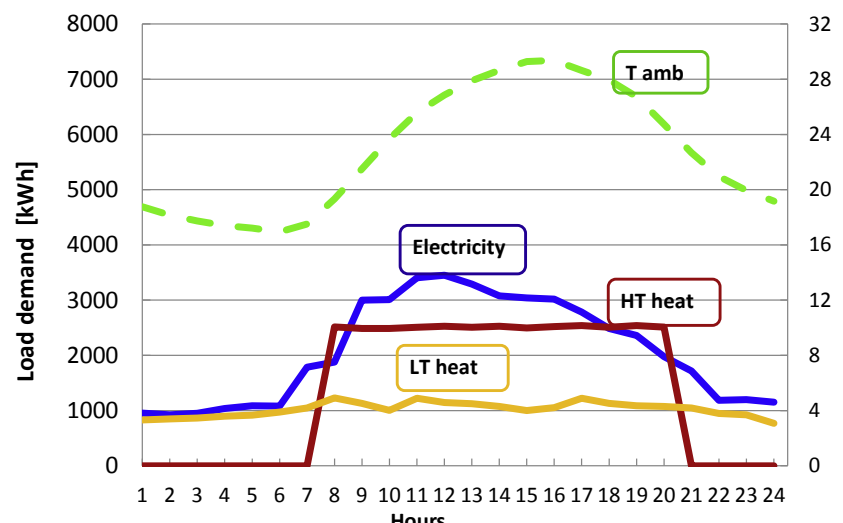

$a, 2)$

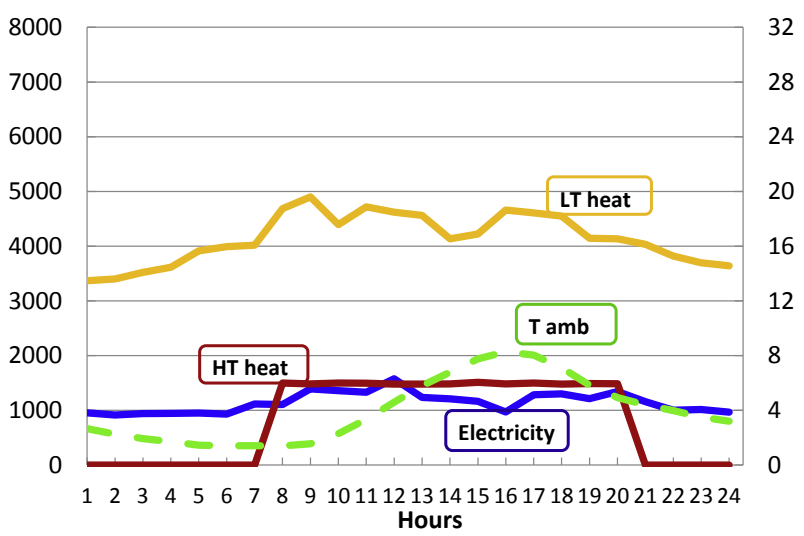

b,2)

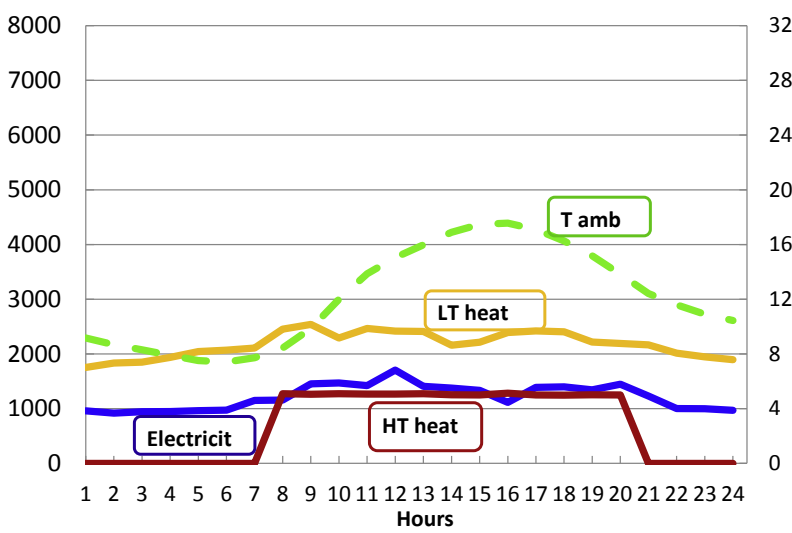

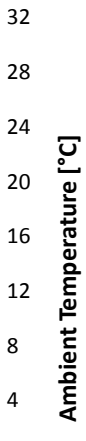

$\mathrm{c}, 2)$

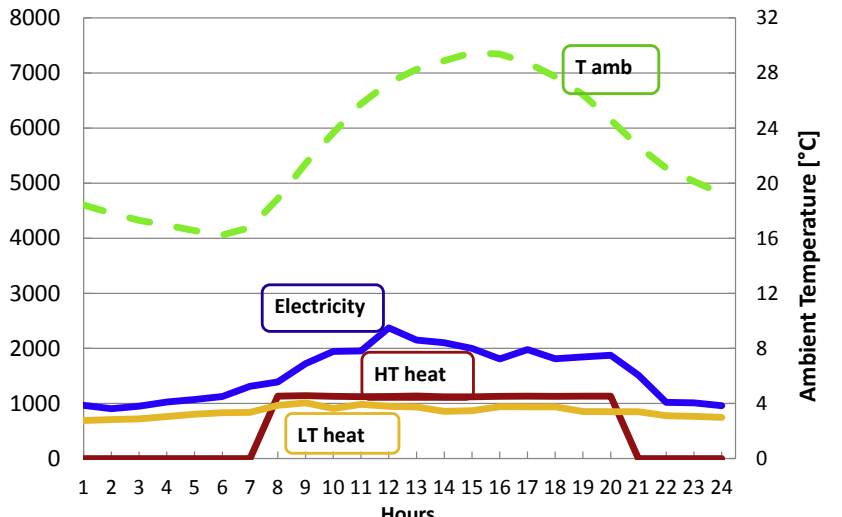

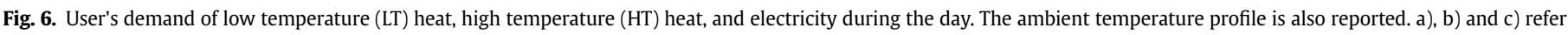
to the winter, mid-season and summer weeks, while 1) and 2) represent the working and non-working days. 

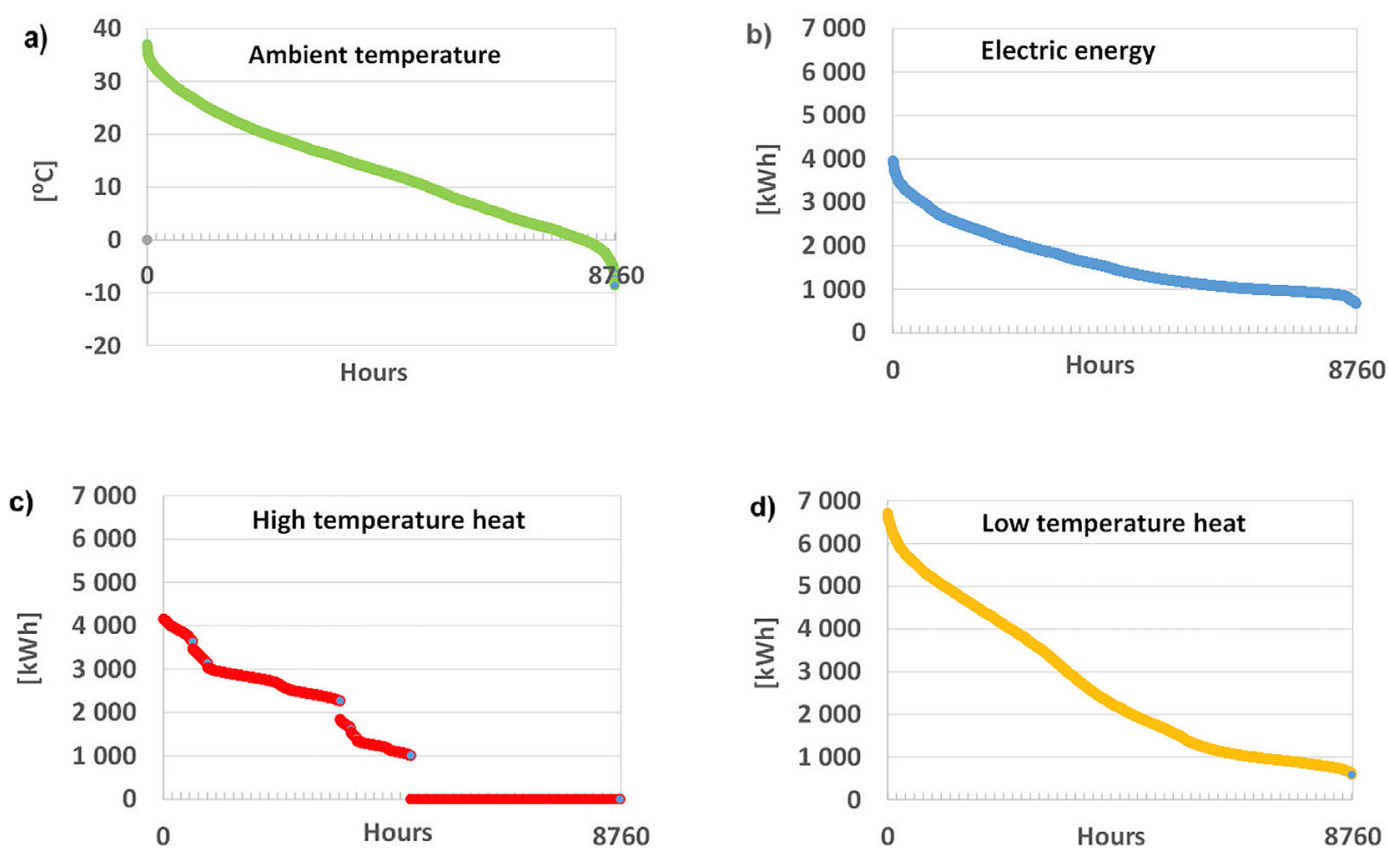

Fig. 7. Annual load duration curve, a) ambient temperature, b) electric energy; c) high temperature heat; d) low temperature heat.
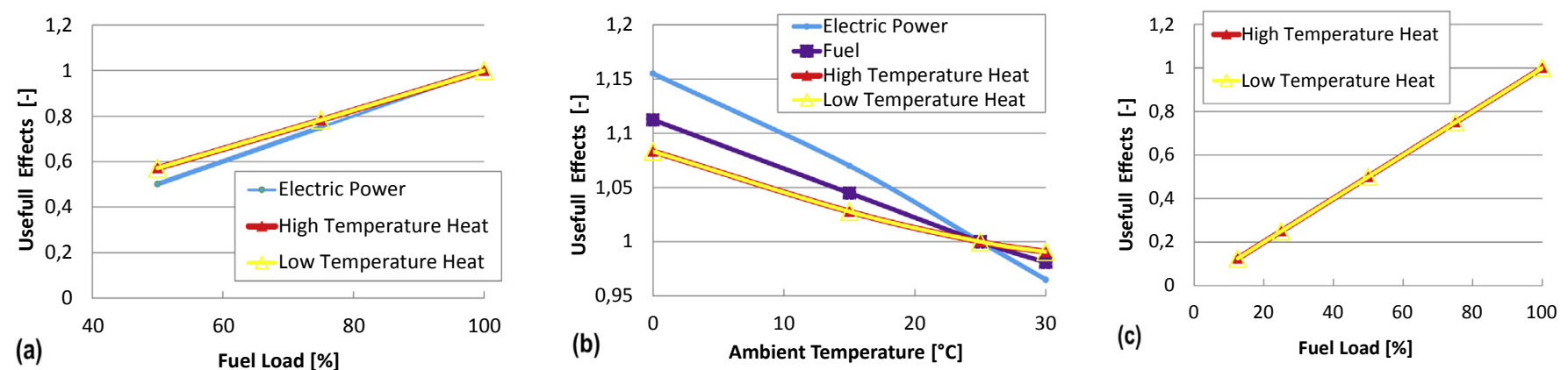

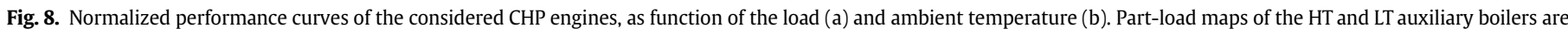
shown in (c).

Table 1

Nominal values utilized to define the performance curves of the units.

\begin{tabular}{ll}
\hline Prime mover (ICE) & \\
\hline Electric efficiency $\eta_{\text {el }}$ & 0.424 \\
Heating thermal efficiency $\eta_{\text {th,HT }}$ & 0.126 \\
Heating thermal efficiency $\eta_{\text {th,LT }}$ & 0.296 \\
Nominal electric output $\left(\mathrm{kW}_{\mathrm{el}}\right)$ & 3393 \\
Nominal HT heat output $\left(\mathrm{kW}_{\mathrm{th}}\right)$ & 1008 \\
Nominal LT heat output $\left(\mathrm{kW}_{\mathrm{th}}\right)$ & 2367 \\
Startup fuel penalty $\left(\mathrm{kW}_{\text {fuel }}\right)$ & 801 \\
\hline Auxiliary boiler & \\
\hline HT boiler nominal power $\left(\mathrm{kW}_{\mathrm{th}}\right)$ & 2035 \\
HT boiler thermal efficiency $\eta_{\text {th,AB,HT }}$ & 0.9 \\
HT Startup fuel penalty $\left(\mathrm{kW}_{\mathrm{fuel}}\right)$ & 226.1 \\
LT boiler nominal power $\left(\mathrm{kW}_{\mathrm{th}}\right)$ & 6000 \\
LT boiler thermal efficiency $\eta_{\mathrm{th}, \mathrm{AB}, \mathrm{LT}}$ & 0.92 \\
LT Startup fuel penalty $\left(\mathrm{kW}_{\mathrm{fuel}}\right)$ & 652.2 \\
\hline
\end{tabular}

The whole year problem consisted in 52 weeks with 20,035 constraints, 13,608 continuous and 6,048 binary variables each. The number of variables depends on the number of intervals of the PWL adopted to model the characteristic curves of the units. In these test cases, five intervals have been considered. The tests were carried out on an Intel Xeon with E3125@3.30GHz CPUs and 16 GB of RAM, with two cores and a time limit of 5,000 s (to solve each MILP weekly subproblem). The computational time required to optimize the whole year of operation without heat storage is about 77,000 s. The first phase which optimized 52 weekly subproblems takes about $1,300 \mathrm{~s}$ in average; this average value is due to a few weeks which require an amount of time one to two orders of magnitude larger than the others. The refinement phase takes in average about $32 \mathrm{~s}$ thanks to the warm start option of the MILP solver. The relative MILP gap for the subproblems was set below $0.1 \%$. The test case with heat storage (S3) reached the time limit for a most of the weekly subproblems and the first optimization (initialization phase) of the whole year required more than two days. However the MILP gap reached values below $1 \%$ in about $1 \mathrm{~min}$, indicating the possibility of considerably decreasing the computational time by setting a higher MILP gap. The increase of computational time compared to the test cases without heat storage is due to fact that the heat storage system greatly increases the number of possible operational solutions to be considered by the MILP solution algorithm.

The objective function, units capacity factor, first principle 
Table 2

Fuel, O\&M, electricity cost assumptions.

\begin{tabular}{|c|c|c|c|}
\hline \multirow{4}{*}{\multicolumn{3}{|c|}{$\begin{array}{l}\text { Fuel cost, } \mathrm{PM}\left(€ / \mathrm{kWh}_{\mathrm{th}} \text {, ref. LHV) }\right. \\
\text { Fuel cost, } \mathrm{AB}\left(€ / \mathrm{kWh} \mathrm{h}_{\mathrm{th}}, \text { ref. LHV }\right) \\
\text { O\&M cost, } \mathrm{PM}\left(€ / \mathrm{kWh}_{\mathrm{el}}\right) \\
\text { O\&M cost, } \mathrm{AB}\left(€ / \mathrm{kWh}_{\mathrm{th}}\right)\end{array}$}} & \multirow{5}{*}{$\begin{array}{l}0.061 \\
0.061 \\
0.0055 \\
0.0001 \\
9-19 h\end{array}$} \\
\hline & & & \\
\hline & & & \\
\hline & & & \\
\hline Electricity prices $^{\mathrm{a}}$ & $1-7,24 \mathrm{~h}$ & $8,20-23 h$ & \\
\hline \multicolumn{4}{|l|}{ Working Day } \\
\hline $\begin{array}{l}\text { sale }\left(€ / \mathrm{kWh}_{\mathrm{el}}\right) \\
\text { Saturday }\end{array}$ & 0.0817 & 0.0964 & 0.0994 \\
\hline purchase $\left(€ / \mathrm{kWh}_{\mathrm{el}}\right)$ & 0.1114 & 0.1272 & 0.1272 \\
\hline sale $\left(€ / \mathrm{kWh}_{\mathrm{el}}\right)$ & 0.0817 & 0.0964 & 0.0964 \\
\hline \multicolumn{4}{|l|}{ Sunday } \\
\hline sale $\left(€ / \mathrm{kWh}_{\mathrm{el}}\right)$ & 0.0817 & 0.0817 & 0.0817 \\
\hline
\end{tabular}

a The consumed electricity, both purchased and produced, is subject to an excise tax which is calculated iteratively based on monthly consumption thresholds ac cording to [9]. It goes from a monthly forfeit of 7320 euros for consumptions above $1,200,000 \mathrm{kWh}_{\mathrm{el}}$ to 0.0125 euro/ $\mathrm{kWh}_{\mathrm{el}}$.

efficiency and primary energy saved ${ }^{6}$ for the 52 weeks of the year are summarized in Fig. 9 while yearly aggregated values for all the cases presented in the paper are shown in Table 3.

The total annual costs of the solutions investigated are the following: $3,472,798 €$ in the rolling horizon case (S1) with almost $10 \%$ increase in the case of no incentives (S2) which reaches $3,816,746 €$. It is worth noting that the difference between the total annual operating cost of the case without incentives and the S1 is essentially the value of the cogeneration credits received. The main differences between the S1 and S2 operation strategies occur in the winter and mid-season because, to meet the yearly incentive constraints, S1 tends to operate the CHP engines at higher loads (higher capacity factors) so compensate the low thermodynamic performance (i.e., primary energy saving) of the summer weeks (see Fig. 9, a and ,c). Therefore, we can conclude that the incentives policy does appreciably affect the optimal operation strategy especially during cold seasons pushing the CHP units towards higher utilization. In addition, the incentives policy has a strong impact on the profitability of cogenerative solutions, pushing it towards saving primary energy (Fig. 9, d).

Comparing cases S1 with S3, it is possible to note that the addition of a thermal energy storage system will allow a reduction of almost $5 \%$ of operative costs going down to $3,313,637 €$. This is due to the fact that the smart use of the thermal energy storage reduces the heat dissipations experienced mainly during summer and mid-season weeks (due to the small heat demand compared to the engines size, see Fig. 9, c), and it allows utilizing the engines at high efficiency (higher loads) for a larger number of hours during winter and mid-season (see the capacity factor values in Fig. 9, b which features an yearly average increase of $12.4 \%$ ). Summarizing, thermal energy storage improves the optimization strategies leading to a $6.7 \%$ increase of PES on yearly bases. Compared to S1 (no thermal storage), $40 \%$ of the overall cost reduction is due to the extra incentives, while the remaining $60 \%$ is due to lower fuel consumption and higher revenues from the electric market. The latter factor plays an important role with a $21.8 \%$ increase in the electricity sold and $11.3 \%$ increase in the electric energy purchased. Indeed, the presence of the storage allows the CHP engines to increase the loads during hours with high electricity selling prices.

\footnotetext{
${ }^{6}$ Figs. 9 and 11 show the amount of primary energy saved in MWh, which is therefore proportional to the incentives that are going to be received, while the value of Primary Energy Savings (PES) of the constraints, Eq. (2), is expressed in relative terms as a \%.
}

Fig. 10 shows the optimal scheduling for a winter working day found with the three cases S1, S2 and S3. In all cases, with the assumed electricity prices, the heat demand drives the operating conditions of the prime movers. Compared to case S2 (no incentives, no efficiency constraints), the introduction of incentives and efficiency constraints (case S1) causes an increase of the load of the CHP engines also during off-peak hours. In peak hours, incentives have no impact because the higher cost of electricity drives the operating conditions (i.e., no difference between S1 and S2): both ICEs operate from 9 to 19. In intermediate hours, the operating conditions depend on the thermal load: ICEs work at full load at 8 and 20, then it reduces between 21 and 22, and finally it turns off from 23. The addition of the thermal storage system (S3) allows to turn on both internal combustion engines from the early morning and then considerably decrease the use of boilers. Indeed in case S3 the capacity factor of the ICE increases from 80 to $95 \%$ in compar-ison to S1.

In order to show the advantages of the proposed rolling horizon algorithm, the same yearly problem has been tackled by means of a more conventional approach imposing the efficiency constraints, Eqs. (1) and (2), on each week. Then, weeks are independently optimized in sequence without adopting a rolling horizon approach. Case S4 refers to the system without thermal storage while case S5 refers to the system with thermal storage. No significant time savings can be noted with respect to the test case with yearly constraints. On the other hand, results for case S4 are substantially different from S1 as shown by aggregated data in Table 3. Indeed, the yearly objective function is almost 3\% worse because the efficiency constraints must be met on weekly basis (which is a much tighter constraint than the yearly basis requirement of the incentive regulation). It is possible to notice in Fig. 11 how the rolling horizon case S1 follows the same path as the case with weekly constraints S4 in the cold season but, during summer time, S1 features much higher revenues because it is economically advantageous to generate electricity and dissipate heat. While strategy S1 can decide to dissipate some heat during summer and then recover efficiency during winter, strategy S4 cannot. As shown in Fig. 11, b), in case S4 the units are not operated during the summer weeks with low thermal load otherwise heat would be wasted and the efficiency constraints would not be met. This brings at much higher electricity generation, about $7 \%$, which in case of higher electricity prices may affect deeper the abovementioned 3\% difference in the objective functions.

When the thermal storage systems is available (cases S3 and S5), the rolling horizon algorithm (S3) and the simplified sequential solution of the weekly problems with efficiency constraints (S5) find very similar solutions. The difference in objective function values reported in Table 3 is within the milp gap of the solver. This is due to the fact that strategy S3 already meets the efficiency constraints on a weekly basis as, thanks to the presence of the storage, only a small amount of heat is wasted and engines are always operated at high loads. This result highlights at the same time the importance of thermal energy storage as well as the importance of using an efficient tool for optimizing the management of storage systems.

\section{Conclusions}

This paper discussed the development of a rolling horizon MILP algorithm for energy system scheduling. The computational results indicate that the proposed algorithm is an effective tool for optimizing the operation scheduling of cogeneration systems subject to yearly-basis efficiency constraints, as required by the European regulation for high efficiency cogeneration. The algorithm consists of two phases: an initialization phase, where we 

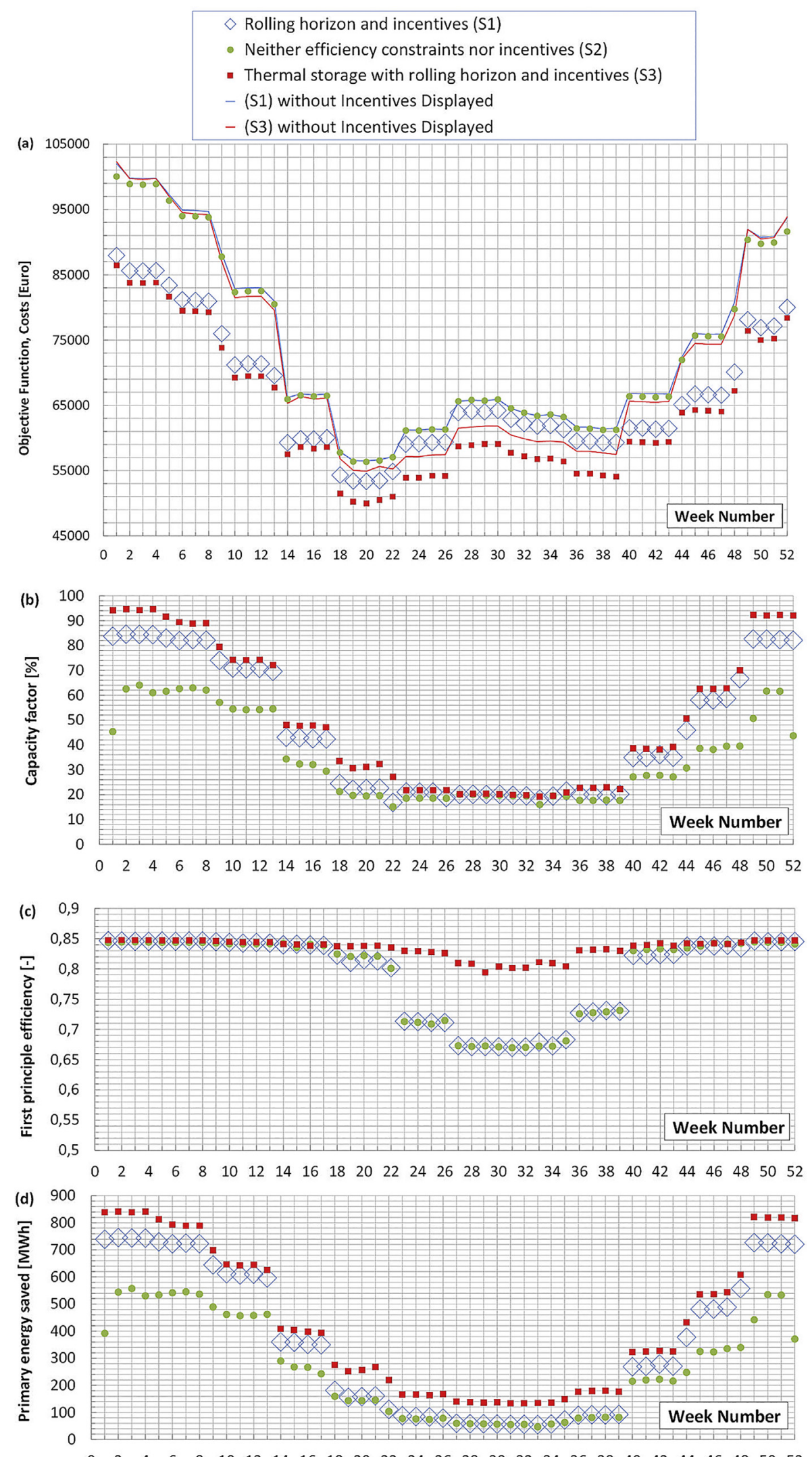

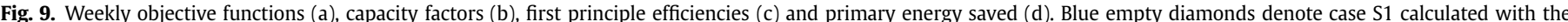

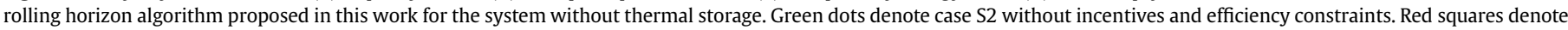

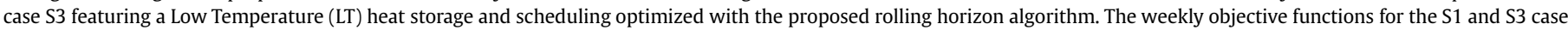

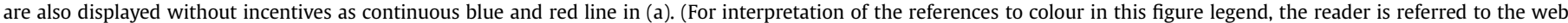
version of this article.) 
Table 3

Yearly aggregated results for the presented test cases.

\begin{tabular}{|c|c|c|c|c|c|}
\hline & Objective Function $[€]$ & White certificates $[€]$ & Capacity factor [\%] & $\eta_{I}[\%]$ & PES [\%] \\
\hline Rolling horizon and incentives (S1) & $3,472,798$ & 367,499 & 46.0 & 79.0 & 22.5 \\
\hline Weekly efficiency constraints and incentives (S4) & $3,571,179$ & 348,130 & 41.3 & 82.0 & 23.5 \\
\hline Neither efficiency constraints nor incentives (S2) & $3,816,746$ & 0 & 34.8 & 79.1 & 22.0 \\
\hline Thermal storage with rolling horizon and incentives (S3) & $3,313,637$ & 429,517 & 51.7 & 83.4 & 24.0 \\
\hline Thermal storage with weekly efficiency constraints and incentives (S5) & $3,310,199$ & 430,380 & 51.0 & 83.5 & 24.0 \\
\hline
\end{tabular}
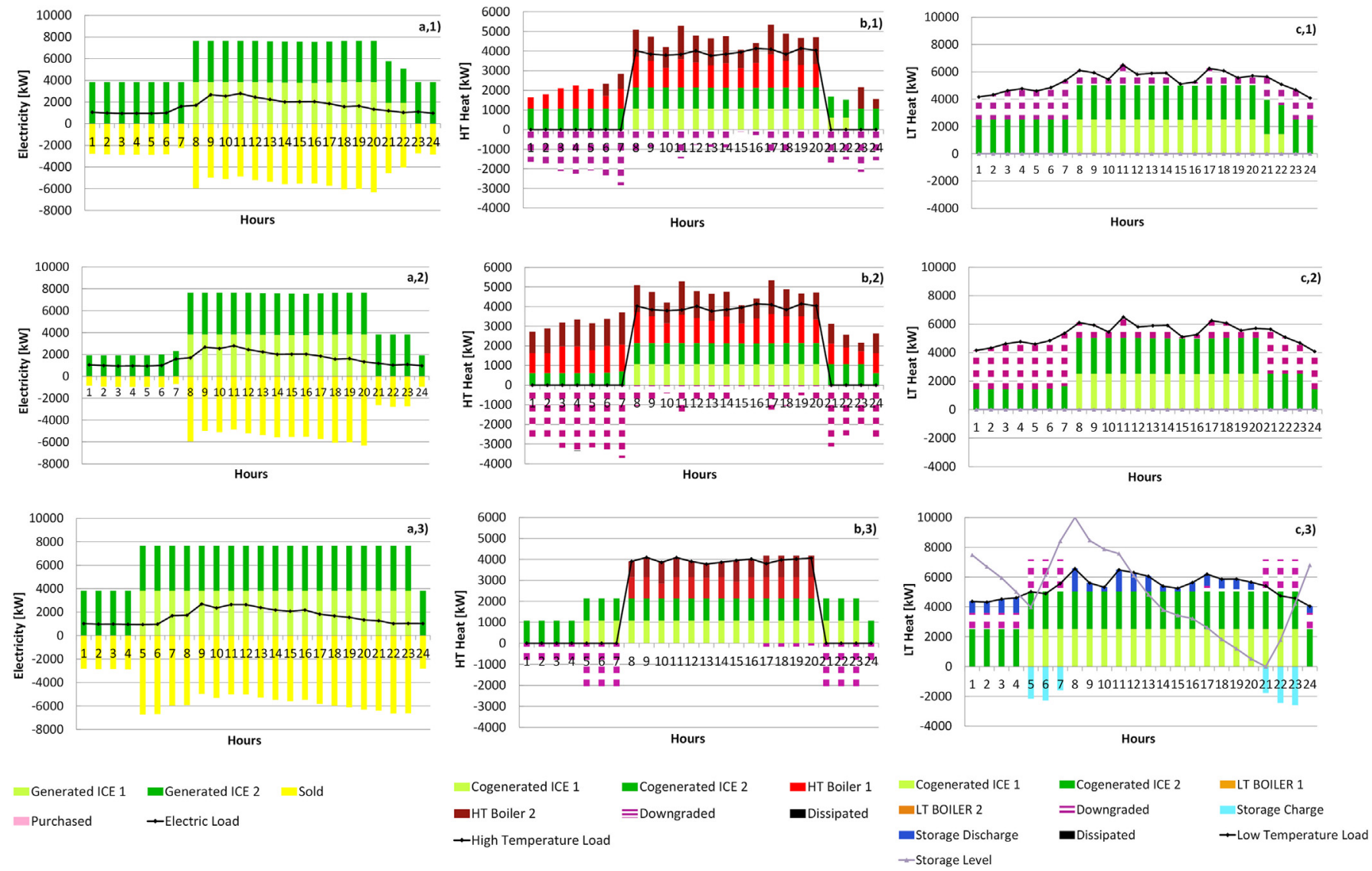

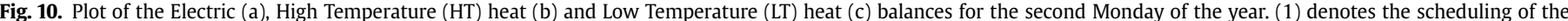

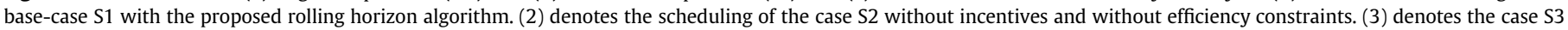
with rolling horizon algorithm and using the low temperature thermal storage.

solve weekly subproblems with aggregated estimates from typical weeks, and a main phase where we solve weekly subproblems with aggregated estimates from previous (optimized) weekly solutions. Thanks to the decomposition of the operating year into weekly subproblems, the computational time required to optimize the whole year of operation on hourly base with a tight relative MILP gap is not impracticable, from 1 day up to 3 days time, making the algorithm an effective scheduling and control tool of cogeneration systems. Indeed, it can be used every week to determine the optimal operation strategy of the installed units. It was also observed that the computational time required to solve the MILP weekly subproblems greatly increases with the presence of storage systems as a consequence of the dependency between time periods. On the other hand, the computational time can be decreased of two orders of magnitude if a slightly larger MILP gap (e.g., 1\%) is adopted. Although the optimality cannot be guaranteed, the analysis of the solutions indicates that the returned operation scheduling is sound from both the economic and thermodynamic point of views.

It is worth highlighting the importance of incentives policy and their impact on the Combined Heat and Power optimal operation. Incentives will reduce the operating costs, objective function, of about $10 \%$ and increase the capacity factor of cogenerative units, especially in cold seasons, leading towards higher savings of primary energy in absolute terms. The proposed yearly rolling horizon optimization strategy allowed an improvement of objective function of almost 3\% in comparison to standard weekly constrained optimization strategies, due to its higher flexibility allowing fulfilling the efficiency constraints on yearly bases and not forcing it per each single week. This implied a larger usage of cogeneration units with 7\% increase in electric energy generation; higher impact on objective function is expected for higher electricity prices. Finally, thermal energy storage deployment and smart management allowed to achieve both the best economic i.e., about 5\% lower operating costs, and thermodynamic indicators. 


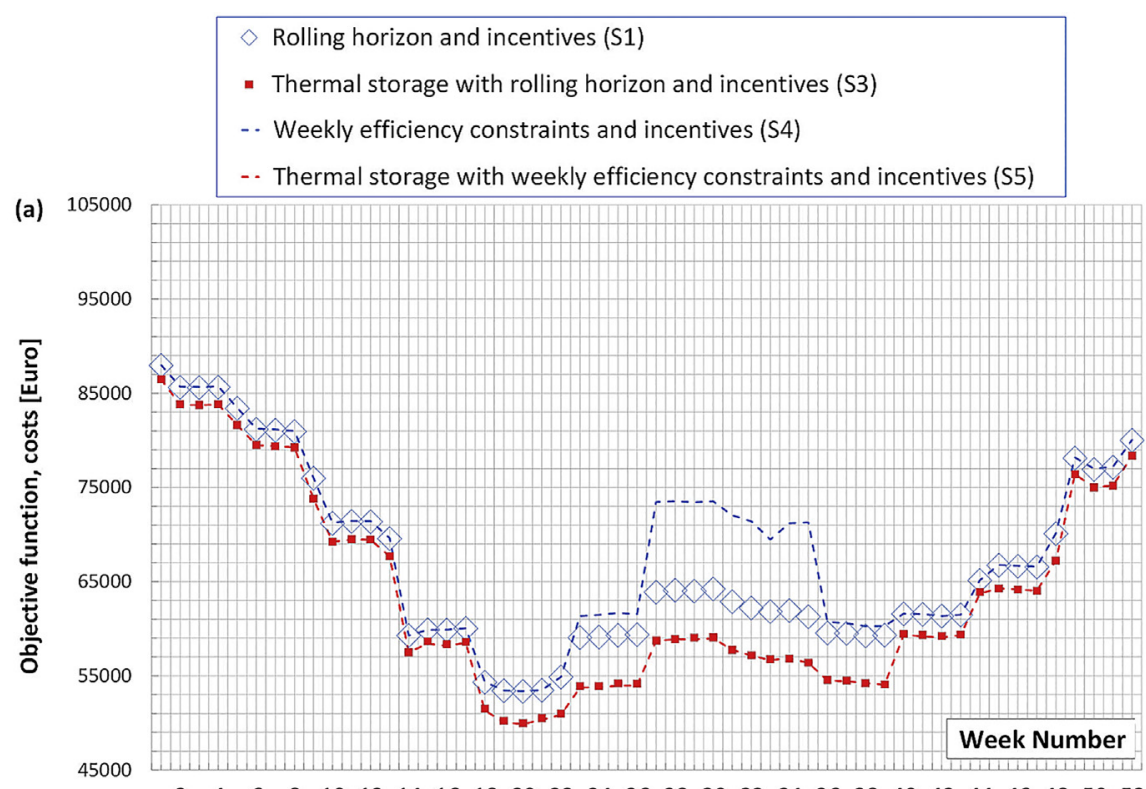

$\begin{array}{llllllllllllllllllllllllll}2 & 4 & 6 & 8 & 10 & 12 & 14 & 16 & 18 & 20 & 22 & 24 & 26 & 28 & 30 & 32 & 34 & 36 & 38 & 40 & 42 & 44 & 46 & 48 & 50 & 52\end{array}$

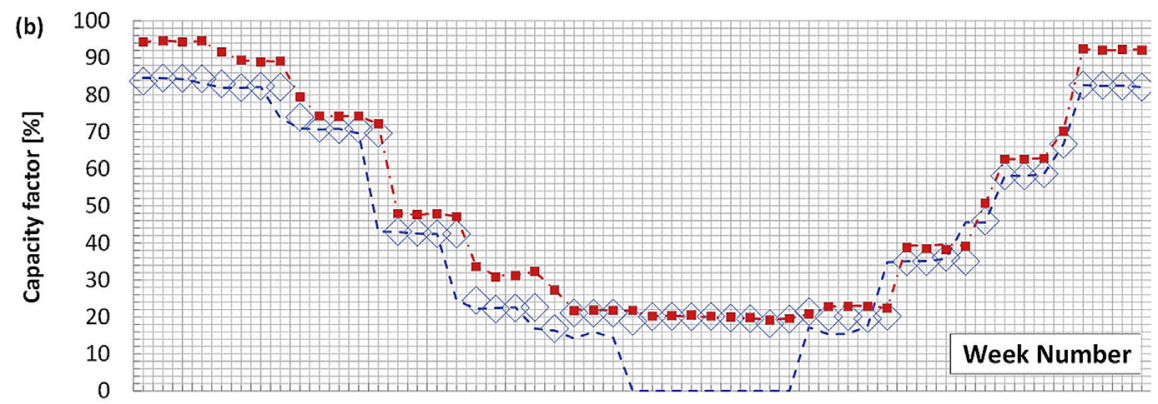

$\begin{array}{llllllllllllllllllllllllll}2 & 4 & 6 & 8 & 10 & 12 & 14 & 16 & 18 & 20 & 22 & 24 & 26 & 28 & 30 & 32 & 34 & 36 & 38 & 40 & 42 & 44 & 46 & 48 & 50 & 52\end{array}$
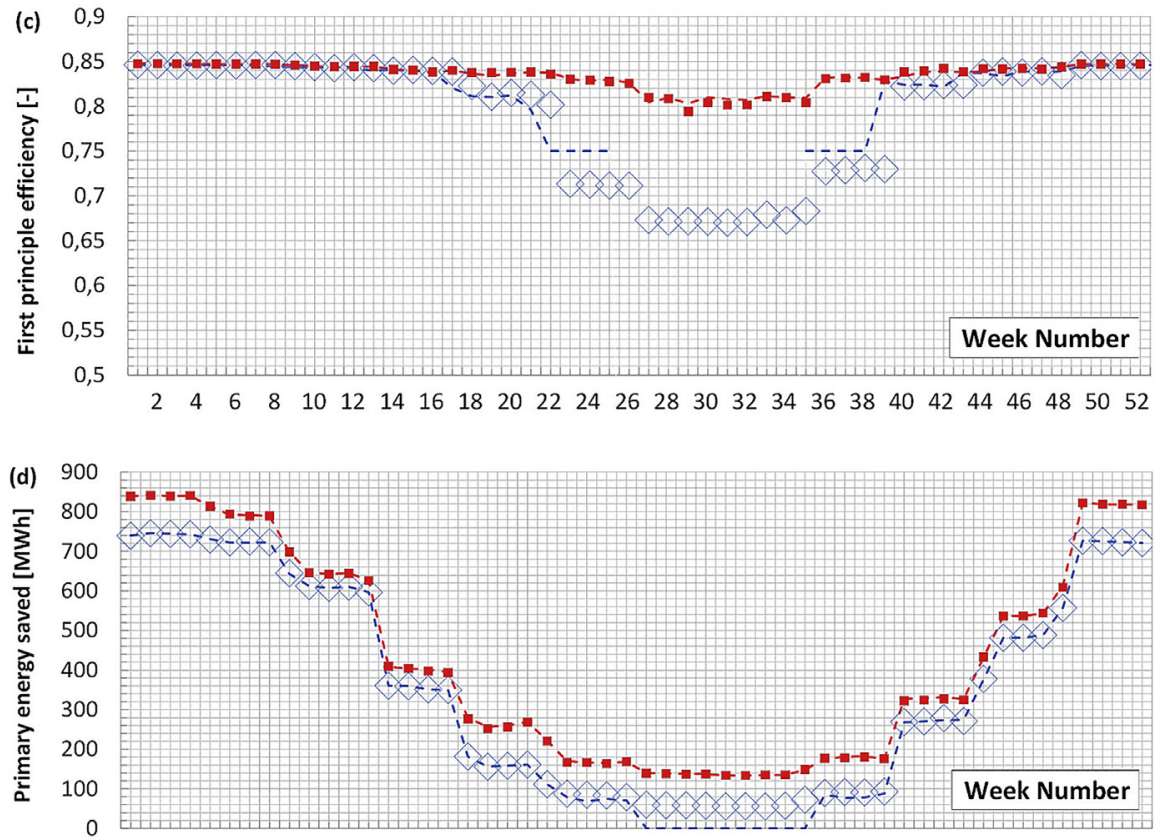

$\begin{array}{llllllllllllllllllllllllll}2 & 4 & 6 & 8 & 10 & 12 & 14 & 16 & 18 & 20 & 22 & 24 & 26 & 28 & 30 & 32 & 34 & 36 & 38 & 40 & 42 & 44 & 46 & 48 & 50 & 52\end{array}$

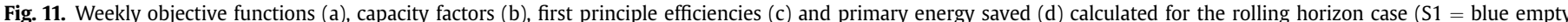

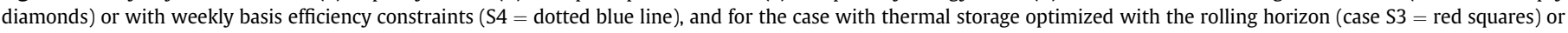

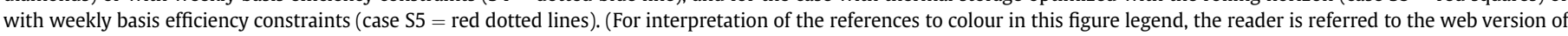
this article.) 


\section{Acknowledgements}

Aldo Bischi was supported by Skoltech NGP Program (SkoltechMIT joint project)

\section{Nomenclature}

\section{Abbreviations and notations}

AB, Aux Boiler Auxiliary Boiler

c specific cost, $[€ / \mathrm{kWh}]$

C Cost, $[€]$

CC Cogeneration Credits, [€]

CHP Combined Heat and Power

CCHP Combined Heat, Cooling and Power

Cold units producing a cooling load.

E Energy [kWh]

el, El Electricity; Units consuming electricity

Ex $\quad$ Excise, $[€]$

$f \quad$ fuel, $[\mathrm{kW}]$

$g \quad$ units performance curves

HT High Temperature

ICE Internal Combustion Engine

$i \quad$ week index

I units consuming fuel

$I_{1} \quad$ units consuming fuel with one degree of freedom

$I_{2} \quad$ units consuming fuel with two degrees of freedom

Inc Incentives, [€]

$k \quad$ current week index.

$l \quad$ storage level, [kWh]

$L \quad$ rolling-horizon loop number

LT Low Temperature

MILP Mixed Integer Linear Programming

$\mathrm{n} \quad$ final yearly loop number

Nw Number of representative weekly periods

$p \quad$ grid losses factor, $[-]$

$P \quad$ units producing electricity

PES Primary Energy Savings

PWL Piece Wise Linear

$q \quad$ heat, $[\mathrm{kW}]$

$\mathrm{RH} \quad$ Rolling Horizon

RMF Reverse-Metering Factor

$T$ hours of the week, [h]; Temperature, $\left[{ }^{\circ} \mathrm{C}\right]$

Th units consuming heat

$u \quad$ heat storage losses, [\%]

y second operative variable

$z \quad$ units on/off status

Greek symbols

$\Delta \quad$ start-ups number

$\eta \quad$ efficiency, [-]

Subscripts and superscripts

abs absorption

cog cogenerated

cold cooling load

cons constant

cust customer request of heat or electricity

diss dissipated heat

deg degraded heat from high to low temperature

el electric energy

f, fuel fuel, [kW]

forf forfeit

h hourly

high high temperature heat

$\begin{array}{ll}\text { i } & \text { i-th unit } \\ \text { I } & \text { first principle thermodynamics } \\ \text { low } & \text { low temperature heat } \\ \text { min } & \text { minimum } \\ \text { max } & \text { maximum } \\ \mathrm{N} & \text { maximum Number of sart-ups } \\ \text { O\&M } & \text { Operation and Maintenance } \\ \text { On/off } & \text { start up operation } \\ \text { purch } & \text { purchased electricity } \\ \text { ref } & \text { reference value for separate electric and thermal } \\ & \text { generation } \\ \text { sold } & \text { sold electricity } \\ \text { stor } & \text { storage heat } \\ \text { t, T } & \text { time period, time horizon } \\ \text { th } & \text { thermal energy } \\ \text { time } & \text { number of hours } \\ \text { tot } & \text { valid for the total number of units } \\ 0 & \text { ambient condition, threshold value }\end{array}$

\section{References}

[1] International Energy Agency (EIA). Cogeneration and district energy. 2009. https://doi.org/10.1787/9789264077171.

[2] Directive 2012/27/EC of the European Parliament and of the Council of 25 October 2012. On energy efficiency (substituting the previous Directive 2004/ 8/EC on the promotion of cogeneration). Official J Eur Union 2012;L315/1.

[3] Obama B. Executive order e accelerating investment in industrial energy efficiency. 2012. http://www.whitehouse.gov/the-press-office/2012/08/30/ executiveorder-.

[4] International Energy Agency (IEA). Energy policies beyond IEA countries Russia 2014. 2014. https://www.iea.org/publications/freepublications/ publication/russia-2014--energy-policies-beyond-iea-countries.html.

[5] Ministero dello Sviluppo Economico. Decreto ministeriale 5 settembre 2011Regime di sostegno per la cogenerazione ad alto rendimento. 2011 [in Italian].

[6] Ministero dello Sviluppo Economico. Linee guida per l'applicazione del Decreto del Ministero dello Sviluppo Economico 5 settembre 2011 - cogenerazione ad Alto Rendimento. 2012 [in Italian].

[7] Macchi E, Campanari S, Silva P. n: La microcogenerazione a gas naturale. Milano: Polipress; Sept. 2005. ISBN 8873980163; Sept. 2005 (in Italian).

[8] Bischi A, Taccari L, Martelli E, Amaldi E, Manzolini G, Silva P, et al. A detailed MILP optimization model for combined cooling, heat and power system operation planning. Energy 2014;74:12-26. https://doi.org/10.1016/ j.energy.2014.02.042

[9] Testo Unico del 26 Ottobre. 1995, aggiornato decreto legge 2 Marzo $2012 \mathrm{n}^{\circ} 16$ in Gazzetta Ufficiale - serie generale - n. 2012. p. 52 [in Italian]

[10] Ovacik IM, Uzsoy R. Rolling horizon algorithms for a single-machine dynamic scheduling problem with sequence-dependent setup times. Int J Prod Res 1994;32(6):1243-63. https://doi.org/10.1080/00207549408956998.

[11] Bassett MH, Pekny JF, Reklaitis GV. Decomposition techniques for the solution of large-scale scheduling problems. AIChE J 1996;42(12):3373-87. https:// doi.org/10.1002/aic.690421209.

[12] Kopanos GM, Pistikopoulos EN. Reactive scheduling by a multiparametric programming rolling horizon framework: a case of a network of combined heat and power units. Industrial Eng Chem Res 2014;53(11):4366-86. https:// doi.org/10.1021/ie402393s.

[13] Jofré A, Rockafellar RT, Wets RJ-B. General economic equilibrium with financial markets and retainability. Econ Theory 2017;63(1):309-45. https:// doi.org/10.1007/s00199-016-1031-y.

[14] Arena C, Cannarozzo M, Mazzola MR. Exploring the potential and the boundaries of the rolling horizon technique for the management of reservoir systems with over-year behaviour. Water Resour Manag 2016. https://doi.org/ 10.1007/s11269-016-1550-0.

[15] Inderfurth K, Kelle P, Kleber R. Dual sourcing using capacity reservation and spot market: optimal procurement policy and heuristic parameter determination. Eur J Oper Res 2013;225(2):298-309. https://doi.org/10.1016/ j.ejor.2012.08.025.

[16] Kopanos GM, Xenos DP, Cicciotti M, Pistikopoulos EN, Thornhill NF. Optimization of a network of compressors in parallel: operational and maintenance planning - the air separation plant case. Appl Energy 2015;146:453-70. https://doi.org/10.1016/j.apenergy.2015.01.080.

[17] Devine MT, Gabriel SA, Moryadee S. A rolling horizon approach for stochastic mixed complementarity problems with endogenous learning: application to natural gas markets. Comput Operations Res 2016;68:1-15. https://doi.org/ 10.1016/j.cor.2015.10.013.

[18] Rakke JG, Stålhane M, Moe CR, Christiansen M, Andersson H, Fagerholt K, et al. A rolling horizon heuristic for creating a liquefied natural gas annual delivery program. Transport Res Part C Emerg Technol 2011;19(5):896-911. https:// 
doi.org/10.1016/j.trc.2010.09.006

[19] Meibom P, Barth R, Hasche B, Brand H, Weber C, O'Malley M. Stochastic optimization model to study the operational impacts of high wind penetrations in Ireland. IEEE Trans Power Syst 2011;26(3):1367-79. https://doi.org/ 10.1109/TPWRS.2010.2070848.

[20] Warrington J, Hohl C, Goulart PJ, Morari M. Rolling unit commitment and dispatch with multi-stage recourse policies for heterogeneous devices. IEEE Trans Power Syst 2016;31(1):187-97. https://doi.org/10.1109/ TPWRS.2015.2391233.

[21] Mayhorn E, Xie L, Butler-Purry K. Multi-time scale coordination of distributed energy resources in isolated power systems. IEEE Trans Smart Grid 2016;3053(c). https://doi.org/10.1109/TSG.2016.2547342. 1-1.

[22] Silvente J, Kopanos GM, Pistikopoulos EN, Espuña A A rolling horizon optimization framework for the simultaneous energy supply and demand planning in microgrids. Appl Energy 2015;155:485-501. https://doi.org/10.1016/ j.apenergy.2015.05.090.

[23] Fang T, Lahdelma R. Optimization of combined heat and power production with heat storage based on sliding time window method. Appl Energy 2016;162:723-32. https://doi.org/10.1016/j.apenergy.2015.10.135.

[24] Hellmers A, Zugno M, Skajaa A, Morales JM. Operational strategies for a portfolio of wind farms and CHP plants in a two-price balancing market. IEEE Trans Power Syst 2016;31(3):2182-91. https://doi.org/10.1109/ TPWRS.2015.2439060.

[25] Dimitriadis AD, Shah N, Pantelides CC. RTN-based rolling horizon algorithms for medium term scheduling of multipurpose plants. Comput Chem Eng 1997;21(97):S1061-6. https://doi.org/10.1016/S0098-1354(97)87643-0.

[26] Shaik MA, Floudas CA, Kallrath J, Pitz HJ. Production scheduling of a largescale industrial continuous plant: short-term and medium-term scheduling. Comput Chem Eng 2009;33:670-86. https://doi.org/10.1016/ j.compchemeng.2008.08.013.

[27] Castro PM, Harjunkoski I, Grossmann IE. Optimal scheduling of continuous plants with energy constraints. Comput Chem Eng 2011;35(2):372-87. https://doi.org/10.1016/j.compchemeng.2010.05.008.

[28] Marquant JF, Evins R, Carmeliet J. Reducing computation time with a rolling horizon approach applied to a MILP formulation of multiple urban energy hub system. Procedia Comput Sci 2015;51:2137-46. https://doi.org/10.1016/ j.procs.2015.05.486.

[29] D'Ambrosio C, Lodi A, Martello S. Piecewise linear approximation of functions of two variables in MILP models. Operations Res Lett 2010;38:39-46. https:// doi.org/10.1016/j.orl.2009.09.005.

[30] Bischi A, Perez-Iribarren E, Campanari S, Manzolini G, Martelli E, Silva P, et al Cogeneration systems optimization: comparison of multi-step and mixed integer linear programming approaches. Int J Green Energy 2017;813:37-41. https://doi.org/10.1080/10447318.2014.986640.

[31] Bischi A, Campanari S, Castiglioni AG, Manzolini G, Martelli E, Silva P, et al. Trigeneration systems optimization: comparison of heuristic and mixed intege linear programming approaches. In: ASME Turbo Expo 2014: Turbine Technical Conference and Exposition (GT2014-27028), Dusseldorf, Germany; 2014. https://doi.org/10.1115/GT2014-27028.

[32] Taccari L, Amaldi E, Martelli E, Bischi A. Short-term planning of cogeneration power plants: a comparison between MINLP and piecewise-linear MILP formulations. Comput Aided Chem Eng 2015;37:2429-34. https://doi.org/ 10.1016/B978-0-444-63576-1.50099-6.

[33] IBM ILOG CPLEX optimizer, http://www-01.ibm.com/software/integration/ optimization/cplex-optimizer/.

[34] Fazlollahi S, Bungener SL, Mandel P, Becker G, Maréchal F. Multi-objectives, multi-period optimization of district energy systems: I. Selection of typica operating periods. Comput Chem Eng 2014;65:54-66. https://doi.org/ 10.1016/j.compchemeng.2014.03.005.

[35] Domínguez-Muñoz F, Cejudo-López JM, Carrillo-Andrés A, Gallardo-Salazar M. Selection of typical demand days for CHP optimization. Energy Build 2011;43: 3036-43. https://doi.org/10.1016/j.enbuild.2011.07.024.

[36] Elsido C, Bischi A, Silva P, Martelli E. Two-stage MINLP algorithm for the optimal synthesis and design of networks of CHP units. Energy 2017;121: 403-26. https://doi.org/10.1016/j.energy.2017.01.014.

[37] Hastie T, Tibshirani R, Friedman J. The elements of statistical learning: data mining, inference and prediction. seco ${ }^{\text {nd }}$ ed. Springer; 2008. 